Tejerizo-García, C., Rodríguez-González, C. y Fernández-Pereiro, M. (2019):

"¿Continuidad o discontinuidad en los castros del noroeste? Una revisión de la secuencia del yacimiento de Viladonga (Castro de Rei, Lugo)". Spal 28.2: 279-313. DOI: http://dx.doi.org/10.12795/spal.2019.i28.22

\title{
¿CONTINUIDAD O DISCONTINUIDAD EN LOS CASTROS DEL NOROESTE? UNA REVISIÓN DE LA SECUENCIA DEL YACIMIENTO DE VILADONGA (CASTRO DE REI, LUGO)
}

\section{CONTINUITY OR DISCONTINUITY OF HILLFORT OCCUPATIONS IN NORTHWESTERN IBERIA? A REVISION OF VILADONGA'S SITE SEQUENCE (CASTRO DE REI, LUGO)}

\author{
CARLOS TEJERIZO-GARCÍA* \\ Instituto de Ciencias del Patrimonio, Consejo Superior de Investigaciones Científicas \\ Grupo de Investigación GIPYPAC. C/Varillas $16,1^{\circ} \mathrm{C}, 37001$, Salamanca. \\ Correo-e: carlos.tejerizo-garcia@incipit.csic.es. (1) https://orcid.org/0000-0001-9479-2720 \\ CELTIA RODRÍGUEZ-GONZÁLEZ \\ Universidade de Santiago de Compostela Grupo de Investigación Síncrisis). Laboratorio de Patrimonio, \\ Paleoambiente e Paisax. Ed. Monte da Condesa s/n, 15782, Santiago de Compostela. \\ Correo-e: celtiarg@gmail.com D https://orcid.org/0000-0002-1996-0947 \\ MARIO FERNÁNDEZ-PEREIRO \\ Universidade de Santiago de Compostel Grupo de Investigación Síncrisis. Laboratorio de Patrimonio, \\ Paleoambiente e Paisaxe Ed. Monte da Condesa s/n, 15782, Santiago de Compostela. \\ Correo-e: mariofdezpereiro@gmail.com (ㄱ) https://orcid.org/0000-0002-7704-6088
}

\begin{abstract}
Resumen: En este artículo se presentan los principales resultados de una revisión de la secuencia del castro de Viladonga (Castro de Rei, Lugo) a partir de un análisis crono-estratigráfico del registro material, con especial relevancia de la cerámica. Este es uno de los principales yacimientos a partir del cual se ha sustentado el relato arqueológico del noroeste peninsular durante el período denominado tradicionalmente como "galaico-romano". Importante fue la contribución historiográfica del sitio al debate sobre la continuidad de las ocupaciones fortificadas en altura durante los momentos tardíos del Imperio Romano y la época sueva, que ha generado diversas interpretaciones sobre la articulación del territorio. Estas interpretaciones partían de la idea de que este castro, y otros similares, estuvieron ocupados entre el siglo II d. C. hasta, al menos, la quinta centuria de forma ininterrumpida. Sin embargo, otras interpretaciones sugerían una cesura en esta secuencia ocupacional, si bien todavía no había sido objeto de una atención específica. La revisión crono-estratigráfica realizada en Viladonga ha permitido proponer una nueva secuencia
\end{abstract}

\begin{abstract}
We present in this paper the main results of a revision of the chronological sequence of Viladonga (Castro de Rei, Lugo) through a chrono-stratigraphic analyses of the material culture, with special regard to pottery assembleages. This hilltop occupation has been one of most important sites through which scholars have developed an archaeological narrative of the so-called "galaic-Roman" period in the northwestern part of the Iberian Peninsula. It was particularly important for the debate around the continuity of this hilltop occupations through the post-Roman and Suevic periods, generating a diversity of interpretations on the settlement articulation in this crucial historical context. These interpretations were based on the idea that this site, and others with similar characteristics, were occupied through a long sequence between the 2 nd century and 5th century AD. However, other interpretations suggested a possible break in the occupational sequence, even though they were not being specifically considered. The chrono-stratigraphic analyses of Viladonga have come to propose a new sequence with two
\end{abstract}


con dos grandes fases de ocupación separadas por un hiato entre los siglos II d. C. y el V d. C. y una fase final de abandono a inicios del siglo VI d. C. La secuencia propuesta supone la reformulación de algunos de los principales paradigmas sobre las transformaciones del poblamiento en el noroeste durante este periodo.

Palabras clave: Secuencia estratigráfica; cerámica; noroeste Iberia; castros; Cadenas Tecnológico-Operativas; poblamiento. major phases of occupation, disrupted by a hiatus between the 2nd and the fourth century and a final phase of abandonment in the 6th century AD. Consequently, this sequence implies a revision of the main paradigms on the transformation of the settlement pattern in the northwestern part of the Iberian peninsula in this period.

Keywords: Stratigraphy; Pottery; Northwestern Iberia; hilltop occupations; Chaîne opératoire; settlement pattern.

\section{INTRODUCCIÓN}

La arqueología de los siglos tardoimperiales y altomedievales del noroeste peninsular, en el territorio correspondiente a la antigua Gallaecia romana, ha sido objeto de una profunda renovación en la última década y media (López Quiroga 2004; Rodriguez Resino 2006). Se trata de un proceso muy particular que partía de una significativa pero irregular tradición de estudios que en los últimos años ha tomado un fuerte impulso debido a la excavación de nuevos contextos y la publicación de un número muy importante de nuevos trabajos (una síntesis en Sánchez Pardo 2010b, 2013). Esta renovación historiográfica ha puesto de relieve, por un lado, la importancia que las transformaciones de los siglos IV-VI d. C. tuvieron para la articulación social y política de las sociedades del noroeste peninsular; y por otro, la necesidad de reconsiderar viejos problemas historiográficos a la luz de estos nuevos planteamientos arqueológicos. Uno de los aspectos que han quedado relativamente soslayados en estos recientes debates, salvo por algunos trabajos específicos (Fernández Pereiro 2017; Sánchez Pardo 2010a, 2012), es la reconsideración del papel que jugaron en este período las ocupaciones fortificadas en altura en época tardoimperial, los conocidos como "castillos de primera generación” (Quirós Castillo 2012). En el caso de la antigua Gallaecia estos sitios tienen además un importante simbolismo. Es sobradamente conocida la importancia que ha jugado la cultura castrexa en la configuración de la arqueología prehistórica gallega y de su identidad (Ayán Vila 2012; González Ruibal 2006-2007). Sin embargo, si bien las secuencias de la Prehistoria Reciente de estos asentamientos han recibido una importante atención, su inserción dentro de los contextos denominados como "tardíos", referidos genéricamente a los siglos posteriores a la cuarta centuria, han sido mucho menos abordados.

Tradicionalmente se mantenía que gran parte de estos castros prehistóricos fueron abandonados una vez el poder imperial romano se instaló definitivamente en la Gallaecia durante época Flavia (Rodríguez Fernández 1994). Hasta inicios de los años 80 la posibilidad de una continuidad en época romana de las ocupaciones castrexas era apenas contemplada (Arias Vilas 1993: 201; Rodriguez Resino 2006: 164). Sin embargo, la creciente excavación de yacimientos en los que aparecía material romano altoimperial y, sobre todo, de producciones tardoimperiales, modificó sustancialmente los paradigmas vigentes. La ocupación de parte de los castros tras el período Flavio, la llamada época "galaico-romana", se presentaba no sólo como una posibilidad sino, lentamente, como una evidencia (Arias Vila 1996; Novo Guisán 1994; Tranoy 1981: 419-422), lo que generó nuevas preguntas e interpretaciones (Sánchez Pardo 2012).

Un aspecto común a prácticamente todos estos trabajos es que, en su mayoría, asumen una ocupación continuada de este conjunto de castros durante toda la época "galaico-romana", esto es, durante los siglos II-V d. C., sin solución de continuidad. Si bien algunos autores cuestionaban esta tajante afirmación planteando que era mejor hablar de reocupaciones o incluso de nuevos poblados fortificados (Arias Vilas 1993: 201), nunca se llegó a definir por completo la cuestión y se mantenía una cierta dependencia interpretativa con respecto a las ocupaciones de la Prehistoria Reciente (Arias Vilas 1993: 203; Tranoy 1981: 419-422). Esto generaba algunos problemas historiográficos de difícil resolución, como por ejemplo, la contemporaneidad entre estos castros y otras categorías de poblamiento como las villas o las ciudades, el estatus jurídico y etno-cultural de las sociedades que los habitaban, o las causas políticas y sociales de la ocupación de estos castros durante época tardoimperial. Curiosamente, la masa empírica en la que se fundamentaban estas interpretaciones no fue objeto de una crítica arqueológica densa, como ha sido puesto de relieve en otras ocasiones (Arias Vilas 1987: 9). 


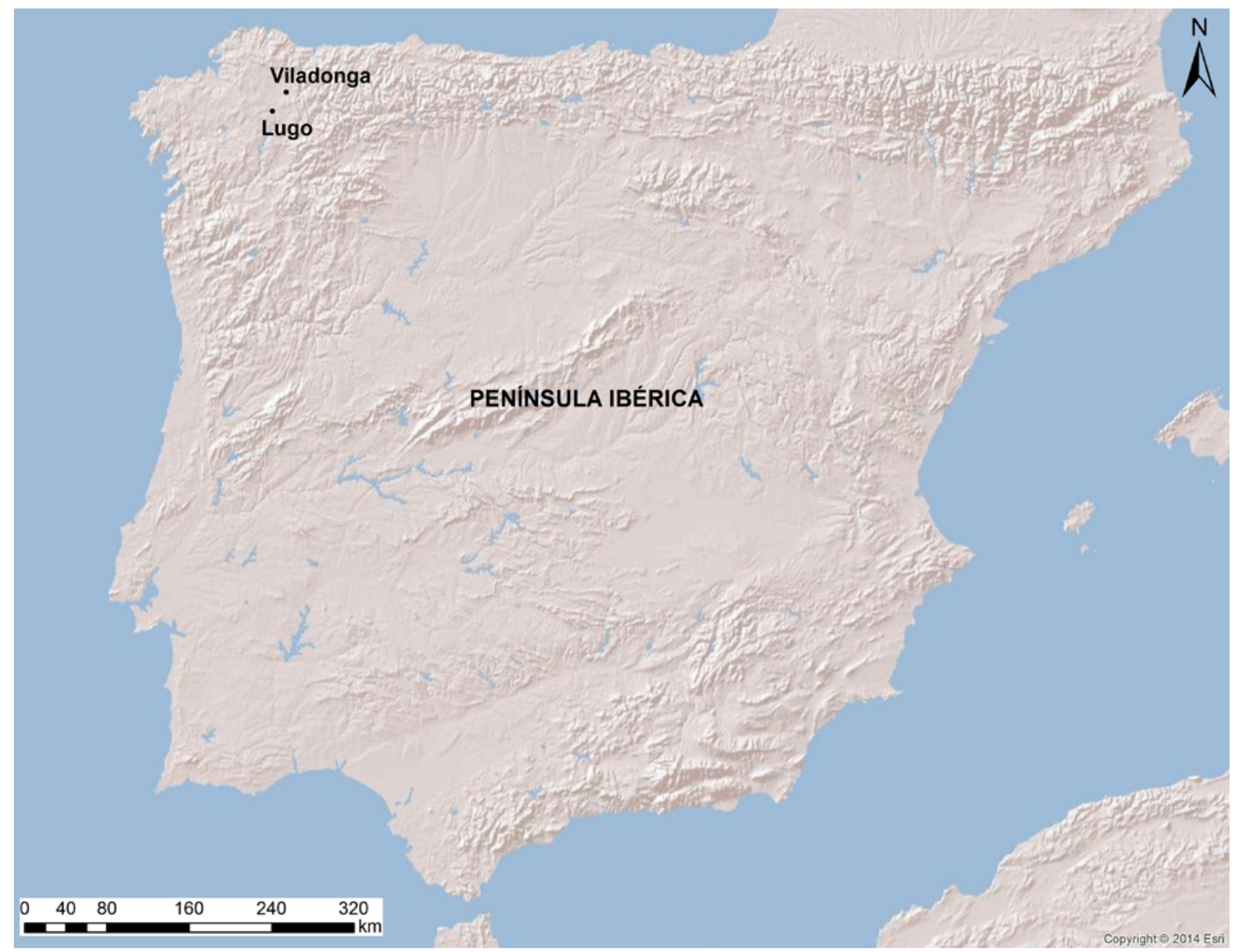

Figura 1. Localización del castro de Viladonga.

En trabajos recientes se ha resaltado la importancia crucial que supone la adecuada datación y secuenciación de este tipo de sitios fortificados para su correcta interpretación dentro de unos contextos históricos específicos (Quirós Castillo 2012). Una primera crítica historiográfica permitió cuestionar las tradicionales secuencias cronológicas asociadas a estos yacimientos (Vigil-Escalera y Tejerizo García 2014) que posteriormente fue aplicada a algunos casos particulares (Fernández Pereiro et al. 2017; Tejerizo García y VigilEscalera Guirado 2017). En estos trabajos se sugería, como agenda de trabajo, realizar análisis similares en otros contextos para seguir contrastando la validez de la hipótesis. En este sentido, el contexto de la Gallaecia tardoimperial y de época sueva se presenta como un espacio privilegiado tanto por su tradición historiográfica, como por la presencia de algunos casos de estudio excepcionales. El castro de Viladonga (fig. 1), por las razones que comentaremos a continuación, es uno de estos casos de estudio. Recientemente tuvimos la ocasión de hacer una revisión de parte del material arqueológico proveniente de las intervenciones más recientes en el yacimiento (un avance en Tejerizo et al. 2018). En este trabajo presentaremos los resultados de esta revisión que, combinada con una crítica estratigráfica, nos permitirá realizar una nueva propuesta de secuenciación del sitio que cuestiona la ocupación continuada de este asentamiento durante toda la época "galaico-romana". Una revisión que, si bien toma como objeto más relevante el análisis cerámico por su potencialidad para la datación y secuenciación del sitio, tendrá en cuenta de forma crítica otros materiales arqueológicos provenientes de las excavaciones, con especial mención a los conjuntos numismáticos o los vidrios. Esta propuesta de secuenciación será posteriormente discutida en el contexto histórico de la Gallaecia tardoimperial y de época sueva, sugiriendo algunas hipótesis interpretativas así como una posible agenda de trabajo. 


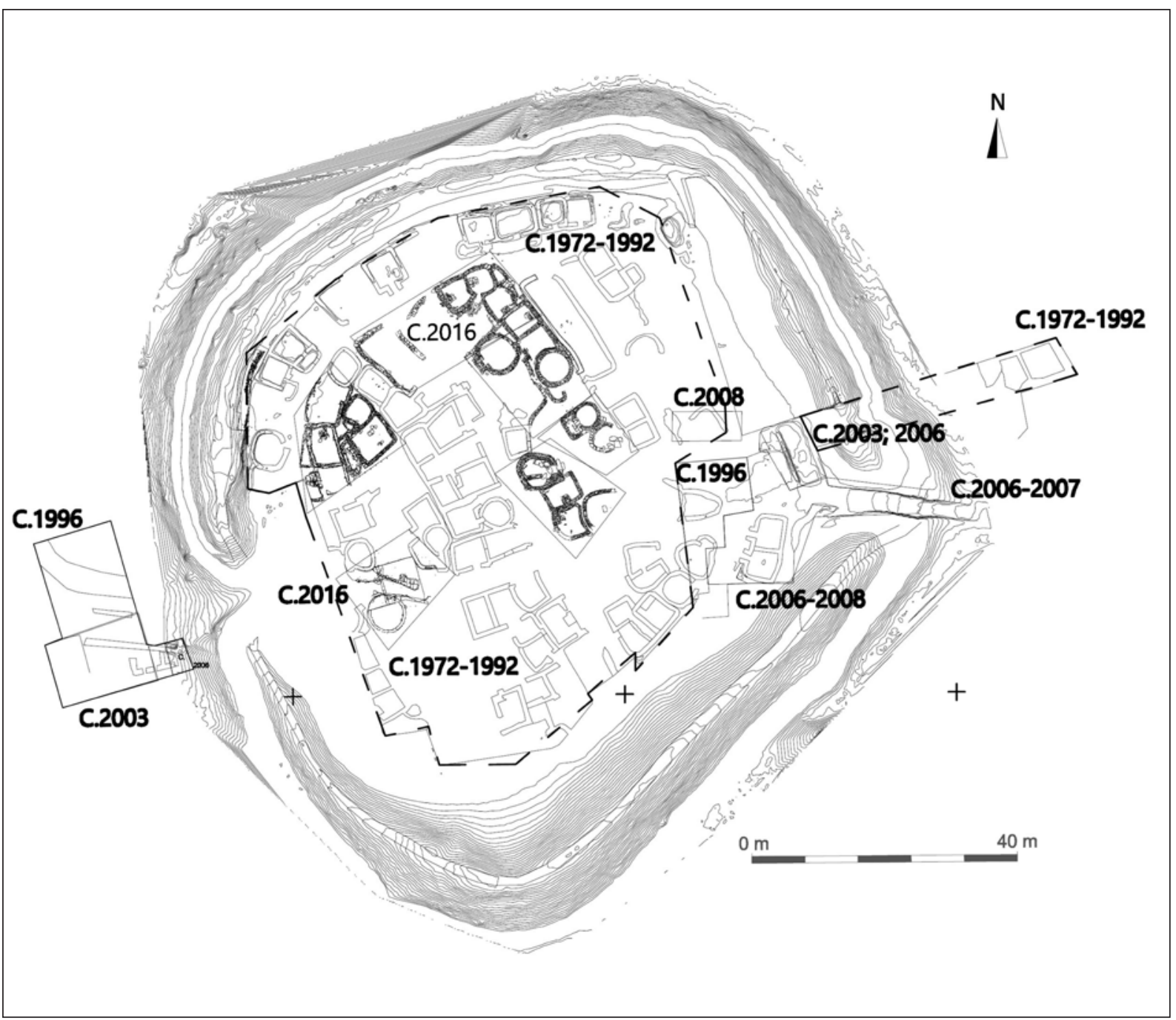

Figura 2. Planimetría de Viladonga con los sectores excavados por campañas.

\section{EL CASTRO DE VILADONGA: CONTEXTUALIZACIÓN Y ANTERIORES PROPUESTAS CRONOLÓGICAS}

El castro de Viladonga (Castro de Rei, Lugo) es un caso excepcional desde muchos puntos de vista. El sitio se localiza a unos $22 \mathrm{k}$. al noreste de la ciudad de Lugo, situado a unos $548 \mathrm{~m}$. de altura sobre el nivel del mar. El sitio abarca alrededor de 4 has. de extensión, de la cuales a la croa, el recinto superior, le corresponden unos $8000 \mathrm{~m}^{2}$. Se encuentra rodeado por una gran muralla, con dos entradas en el eje Este-Oeste, y con un sistema defensivo complejo compuesto por fosos y antecastros (fig. 2). Las construcciones exhumadas utilizan la piedra local de granito, esquisto, pizarra y cuarzo blanco (Arias Vilas et al. 2013: 63).

Uno de los aspectos más sobresalientes del castro de Viladonga como yacimiento arqueológico es la extensión excavada; un total de $6476 \mathrm{~m}^{2}$, que supone cerca de un $80 \%$ de la croa. Esta gran extensión excavada es una consecuencia de una historiografía muy particular y de intervenciones reiteradas sobre el sitio, dividida en tres etapas distintas desde 1970 hasta la actualidad (una síntesis en Arias Vilas et al. 2013: 23-34). Estas intervenciones continúan hoy día, centradas en la limpieza, restauración y excavación de las últimas partes de las secuencias de las estructuras ya exhumadas durante la década de 1970, así como a la ampliación de las excavaciones en la zona este del sitio (cuyos avances 
Tabla 1. Características de las campañas analizadas

\begin{tabular}{|c|c|c|c|c|}
\hline CAMPAÑA & ENTIDAD & SECTORES INTERVENIDOS & 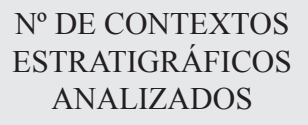 & $\begin{array}{l}\text { FRAGMENTOS } \\
\text { CERÁMICOS } \\
\text { ANALIZADOS }\end{array}$ \\
\hline 1996 & Terra Arqueos & $\begin{array}{l}\text { Ampliación área excavada en antecastro } \\
\text { oeste y trabajos en croa }\end{array}$ & 53 & 2125 \\
\hline 2003 & AXA Arqueología & $\begin{array}{l}\text { Camino este de entrada principal. Para- } \\
\text { mento interior de la muralla. Ampliación } \\
\text { trabajos en antecastro oeste. }\end{array}$ & 36 & 1147 \\
\hline 2006 & AXA Arqueología & $\begin{array}{l}\text { Excavaciones entrada principal. Barrio este } \\
\text { de la croa. Antecastro oeste }\end{array}$ & 25 & 172 \\
\hline 2007 & AXA Arqueología & $\begin{array}{l}\text { Excavación de vivienda exhumada en cam- } \\
\text { paña anterior }\end{array}$ & 33 & 403 \\
\hline 2008 & AXA Arqueología & $\begin{array}{l}\text { Excavación de la entrada principal de la } \\
\text { croa y parte interior a ambos lados de la en- } \\
\text { trada. }\end{array}$ & 40 & 908 \\
\hline \multirow[t]{2}{*}{2016} & Terra Arqueos & $\begin{array}{l}\text { Excavación de los sectores } 12 \text { y } 13 \text { y la en- } \\
\text { trada de la croa. }\end{array}$ & 41 & 996 \\
\hline & & TOTAL & 228 & 5751 \\
\hline
\end{tabular}

pueden leerse en http://intervencionviladonga17.blogspot.com/).

La tradicional cronología propuesta para el sitio ha generado un cierto consenso académico. De forma reiterada se ha datado el yacimiento en "época castrexa" con una importante ocupación en "época galaico-romana", lo que equivalía a situar la ocupación del sitio entre la Segunda Edad de Hierro y un momento indeterminado entre los siglos IV y VI d. C., sin solución de continuidad aparente; si bien se ha venido restringiendo una ocupación "más intensa" entre los siglos II y V d. C. (con ligeros matices, es lo que se ha defendido en Arias Vilas 1996: 181; Arias Vilas y Fábregas Valcarce 2003: 194; Ayán Vila 2012; Caamaño Gesto y López Rodríguez 1984; Llana Rodríguez y Varela Arias 2001; Rodríguez Fernández 1994; Rodriguez Resino 2006: 170; Sánchez Pardo 2010a: 135). Una propuesta ligeramente distinta sería la de M.R. Lovelle y J.L. Quiroga, que extenderían la ocupación del sitio hasta el siglo VII e incluso el VIII d. C. (Lovelle y López Quiroga 2000: 60-64), si bien en otro trabajo limitan su ocupación "desde finales del s.III hasta las primeras décadas del s.V" (López Quiroga y Lovelle 1999: 361). En cualquier caso, todas estas propuestas asumían una continuidad en la ocupación que, sin embargo, no corresponde con los análisis crono-estratigráficos realizados y que presentaremos en las siguientes secciones.

\section{ANÁLISIS CRONO-ESTRATIGRÁFICO DEL MATERIAL ARQUEOLÓGICO DEL YACIMIENTO}

\subsection{Apuntes metodológicos}

Con el objetivo de revisar la secuencia de ocupación del Castro de Viladonga, se propone como metodología un análisis de todos aquellos materiales arqueológicos exhumados en el yacimiento a través de un método crono-estratigráfico. Así, se parte de una crítica estratigráfica como la única forma de generar secuencias relativas y absolutas de actividades (o no-actividades) en el sitio. Es decir, tomar el contexto arqueológico en cuanto unión de conjunto de materiales y procesos de formación en estratigrafías concretas (Schiffer 1990), como unidad básica de análisis. De esta manera, se ha prestado una mayor atención a aquellas intervenciones en las que se utilizó una metodología estratigráfica. Específicamente, se han analizado los materiales exhumados en las campañas de 1996, 2003, 2006, 2007, 2008 y 2016, detalladas en la tabla 1 .

Si bien se tendrán en cuenta todos los datos tipocronológicos derivados de los diversos materiales arqueológicos en su conjunto como ha sido propuesto en otros trabajos de similar naturaleza (King 2013; Tejerizo García y Vigil-Escalera Guirado 2017), también 
es cierto que no todos presentan las mismas potencialidades para los objetivos propuestos. En este sentido, se prestará especial atención a la cerámica por su utilidad como elemento datante de los contextos arqueológicos (Orton et al. 1997). Gracias al desarrollo de los estudios cerámicos de época post-romana en las últimas dos décadas (recientes síntesis en Martín Viso et al. 2018; Vigil-Escalera y Quirós Castillo 2016), actualmente estamos en disposición de una cantidad suficiente de datos para afrontar con un nivel mayor de detalle el material cerámico de Viladonga, tanto en sus aspectos cronológicos -como elemento datante de los contextos- como en los tecnológico-productivos. Así, presentaremos un análisis de la cerámica del sitio a partir del reconocimiento macroscópico de las diferentes Cadenas Tecnológico-Operativas (CTO o CTOs en adelante) presentes en el conjunto vascular (apartado 2.2), delimitando sus características principales y su presencia relativa tanto en el conjunto como en cada uno de los contextos, como se ha venido proponiendo en estudios cerámicos similares (Tejerizo García 2016; Tejerizo García y Vigil-Escalera Guirado 2017; Vigil-Escalera 2003).

Junto con el análisis cerámico, se prestará una atención particular a otros materiales muy útiles para la obtención de una secuenciación del yacimiento, como son las monedas y los vidrios (apartado 3.3). Seguidamente, se analizarán las dataciones radiocarbónicas realizadas en el sitio (apartado 3.4). Finalmente, y a partir de la información extraída, se realizará un análisis específico de una secuencia estratigráfica completa del yacimiento que permita contrastar las hipótesis vertidas anteriormente (apartado 3.5). A partir de las conclusiones extraídas se propondrá una secuencia para el yacimiento de Viladonga (apartado 4).

\subsection{Análisis de los conjuntos cerámicos del yacimiento}

La gran extensión excavada en Viladonga ha conllevado la exhumación de una de las colecciones cerámicas más numerosa asociada a las ocupaciones fortificadas tardoimperiales de toda la península ibérica. Sin embargo, todavía no existe un estudio sistemático salvo algunos trabajos aislados, asociados al estudio de la $\mathrm{si}$ gillata del sitio y algunas producciones de imitación (Caamaño Gesto y López Rodríguez 1984; Juan Tovar 2012a), las decoraciones de la cerámica prehistórica (Dorrego Martínez y Rubiero Da Pena 1998) o a consideraciones generales dentro de estudios más amplios del yacimiento (Arias Vilas et al. 2013). Recientemente tuvimos la oportunidad de publicar una primera aproximación a los conjuntos cerámicos tardíos (Tejerizo García et al. 2018), que aquí ampliamos notablemente. En general, se ha venido considerando el conjunto de la cerámica como representativa del momento "castrexo-galaico-romano" (así están consignados en los inventarios del Museo del Castro de Viladonga), datada generalmente entre los siglos II d. C. y el s. V d. C.

El análisis cerámico que aquí presentamos se llevó a cabo entre el 25 y el 31 de mayo de 2017 en el Museo del Castro de Viladonga. El número de fragmentos totales analizados suma 5751 (aproximadamente un 8\% del total exhumado; cuyo total podría llegar a cerca de 74000 fragmentos), con un peso total de $110,7 \mathrm{~kg}$ y un Número Mínimo de Individuos de 1693 repartidos en 228 contextos estratigráficos distintos. Por su parte, el índice de fragmentación (IF) calculado, con una media de 0,07 , indica un alto grado de fragmentación del material, reflejado en el bajo número de piezas completas o con perfil completo localizadas y el escaso tamaño de los fragmentos.

Se han diferenciado hasta 13 CTOs distintas dentro del conjunto. Sus características y cuantificaciones se resumen en la tabla 2.

\subsubsection{El inicio de la secuencia cerámica: Las producciones de época prehistórica}

Del análisis global del conjunto destaca la masiva presencia de las cadenas tecnológicas definidas como "prehistóricas", que equivalen a la mitad del material analizado (52,74\% de los fragmentos y 50,33\% del peso) y que por ello merecen algunos comentarios particularizados. Por su parte, esta CTO marcaría las producciones más antiguas del sitio (fig. 3) y, por lo tanto, una aproximación a las primeras cronologías de ocupación de Viladonga. Parte del material proveniente de las excavaciones más antiguas fue objeto de una publicación específica (Dorrego Martínez y Rubiero Da Pena 1998).

Su alto número dentro del conjunto tiene una explicación fundamentalmente estratigráfica y de selección de los contextos para el análisis. Como ya se comentó, se analizaron aquellos conjuntos pertenecientes a las excavaciones más recientes del sitio, que incluyeron intervenciones sobre sectores anteriormente excavados con el objetivo de agotar la estratigrafía y consolidar las estructuras exhumadas, caso por ejemplo de las campañas de 2008 y de 2016. Esto, lógicamente, 
Tabla 2. CTOs documentadas en el conjunto cerámico analizado.

\begin{tabular}{|c|c|c|c|c|c|c|}
\hline СТО & Descripción & Frag $\left(n^{0}\right)$ & Frag $(\%)$ & Peso (gr) & Peso $(\%)$ & IF \\
\hline PREH & $\begin{array}{l}\text { Producciones realizadas a mano o me- } \\
\text { diante sistemas de rotaciones lentas de } \\
\text { cocciones mixtas muy irregulares y muy } \\
\text { poco depuradas con desgrasantes de me- } \\
\text { diano y gran tamaño de cuarzo y mica. }\end{array}$ & 3033 & 52,74 & 55701 & 50,33 & 0,05 \\
\hline TS & Terra sigillata genérica o indeterminada & 26 & 0,45 & 164 & 0,15 & 0,15 \\
\hline TSHT lisa & - & 91 & 1,6 & 549 & 0,5 & 0,16 \\
\hline $\begin{array}{l}\text { TSHT decorada a } \\
\text { molde }\end{array}$ & - & 28 & 0,48 & 219 & 0,2 & 0,12 \\
\hline TSHT estampillada & - & 4 & 0,07 & 43 & 0,04 & 0,09 \\
\hline TSHT (total) & Terra sigillata Hispánica Tardía & 123 & 2,14 & 811 & 0,73 & 0,15 \\
\hline CIS & $\begin{array}{l}\text { Cerámica Imitación de Sigillata (CIS). } \\
\text { Normalmente con presencia de barni- } \\
\text { ces color ocre y avellanas con desgra- } \\
\text { santes de pequeño y mediano tamaño de } \\
\text { cuarzo y mica plateada. }\end{array}$ & 7 & 0,12 & 173 & 0,16 & 0,04 \\
\hline CCRA & $\begin{array}{l}\text { Cerámica a torno rápido y cocción oxi- } \\
\text { dante con pastas bien depuradas con } \\
\text { desgrasantes de mediano tamaño de } \\
\text { cuarzo. }\end{array}$ & 20 & 0,35 & 299 & 0,27 & 0,06 \\
\hline CCRB & $\begin{array}{l}\text { Cerámica a torno rápido y cocciones } \\
\text { mixtas (tendente a oxidantes) de pastas } \\
\text { poco depuradas con desgrasantes de me- } \\
\text { diano y gran tamaño de cuarzo, mica, } \\
\text { mica plateada y chamota. }\end{array}$ & 789 & 13,72 & 16219 & 14,65 & 0,04 \\
\hline CCRC & $\begin{array}{l}\text { Cerámica a torno rápido y cocciones } \\
\text { oxidantes o mixtas de pastas semidepu- } \\
\text { radas con desgrasantes de mediano ta- } \\
\text { maño de cuarzo y mica. }\end{array}$ & 91 & 1,58 & 2938 & 2,65 & 0,03 \\
\hline Engobada & $\begin{array}{l}\text { Producciones a torno rápido de coccio- } \\
\text { nes mixtas, normalmente oxidante al ex- } \\
\text { terior y reductora al interior. Presencia } \\
\text { de abundantes desgrasantes de mica pla- } \\
\text { teada de mediano y gran tamaño. }\end{array}$ & 537 & 9,34 & 10530 & 9,51 & 0,05 \\
\hline TRA & $\begin{array}{l}\text { Cerámica a torno rápido y cocción re- } \\
\text { ductora, bien depurada con desgrasantes } \\
\text { medianos y pequeños de cuarzo y mica } \\
\text { plateada de buena calidad. }\end{array}$ & 3 & 0,05 & 76 & 0,07 & 0,04 \\
\hline TRB & $\begin{array}{l}\text { Cerámica a torno rápido y cocción re- } \\
\text { ductora, escasamente depurada con des- } \\
\text { grasantes de mediano y gran tamaño (> } \\
5 \mathrm{~mm} \text {.) de chamota, cuarzo y mica pla- } \\
\text { teada y dorada. }\end{array}$ & 643 & 11,18 & 15822 & 14,30 & 0,04 \\
\hline
\end{tabular}




\begin{tabular}{|l|l|c|c|c|c|c|}
\hline \multicolumn{1}{|c|}{ CTO } & \multicolumn{1}{|c|}{ Descripción } & Frag (n ${ }^{\circ}$ & Frag (\%) & Peso (gr) & Peso (\%) & IF \\
\hline TRB1 & $\begin{array}{l}\text { Cerámica a torno rápido y cocción ge- } \\
\text { neralmente mixta tendente a reductora. } \\
\text { Presencia de desgrasantes de gran ta- } \\
\text { maño de mica plateada, cuarzo y cuar- } \\
\text { cita. }\end{array}$ & 25 & 0,43 & 634 & 0,57 & 0,03 \\
\hline TRC & $\begin{array}{l}\text { Cerámica a torno rápido, semidepuradas } \\
\text { y con desgrasantes de mediano tamaño } \\
\text { de cuarzo y mica plateada. Variante de } \\
\text { pastas muy jabonosas. }\end{array}$ & 174 & 3,03 & 2813 & 2,54 & 0,06 \\
\hline TLB & $\begin{array}{l}\text { Producciones realizadas a torno bajo o a } \\
\text { mano, de cocciones mixtas (con diver- } \\
\text { sas variantes) y escasamente depuradas } \\
\text { con desgrasantes medios y grandes de } \\
\text { cuarzo, cuarcita, chamota y abundante } \\
\text { mica plateada. Normalmente asociado a } \\
\text { formas abiertas tipo fuentes. }\end{array}$ & 23 & 0,40 & 1575 & 1,42 & 0,01 \\
\hline INDET & \begin{tabular}{l} 
Producciones indeterminadas \\
\hline
\end{tabular}
\end{tabular}

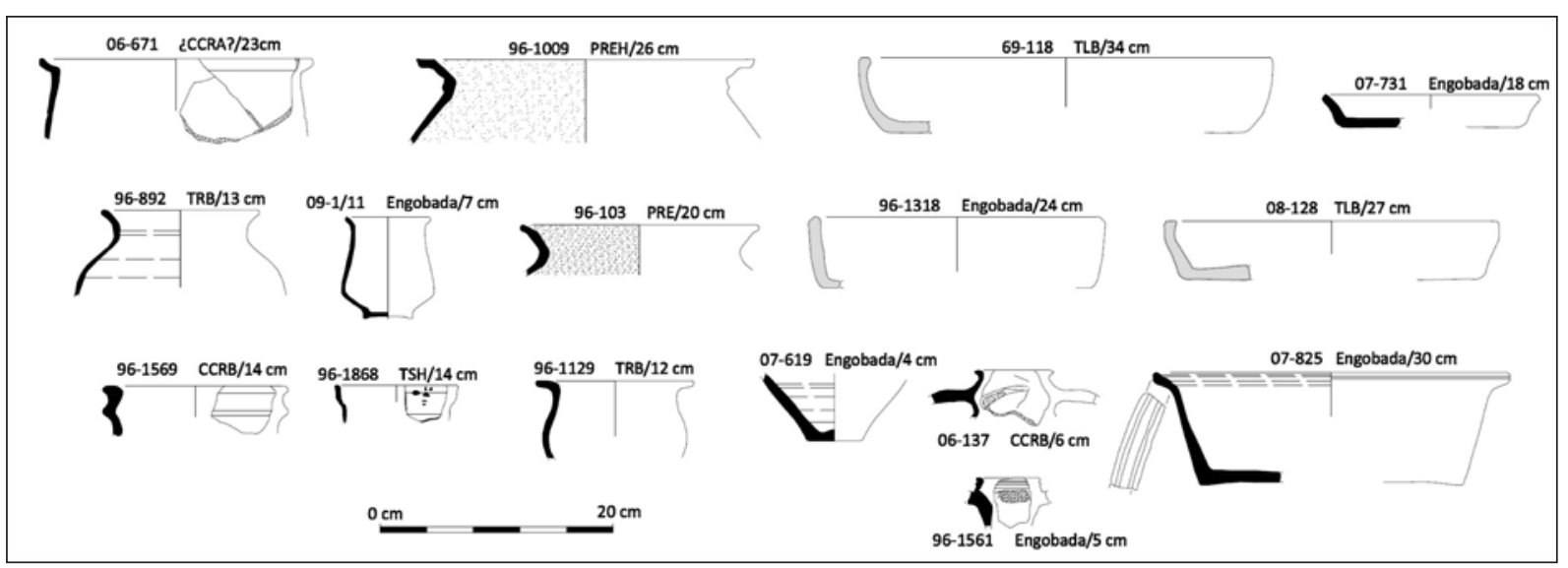

Figura 3. Cerámica de Viladonga. Dibujos de los autores.

afectó sobre todo a los estratos inferiores del sitio, aquellos con mayor presencia de cerámica prehistórica. El hecho de que un tanto por ciento muy alto provengan de este tipo de estratigrafías parciales de los momentos más antiguos del sitio - cerca de 2097 fragmentos, un total de $36 \%$ de fragmentos en 86 Unidades Estratigráficas distintas- explicaría la aparente sobrerrepresentación de la cerámica prehistórica sobre otras producciones pero que, como veremos, encuentra una coherencia en el análisis de estratigrafías completas específicas (ver apartado 3.5.).

En conjunto, se trata de una CTO que se diferencia con relativa facilidad por estar realizadas a mano, con pastas muy poco depuradas cocidas en ambientes mixtos que dejan una factura muy irregular y particularizadas por la presencia de bruñidos muy característicos tanto en el exterior como en el interior de la cerámica (este bruñido interior es el que permite caracterizarlo frente a otras producciones tecnológicamente similares, como la TRB o la TRB1, que carecen de ellos o se presentan únicamente al exterior). Así mismo, se asocian a decoraciones muy características, como son las incisiones y bruñidos en forma de líneas oblicuas, horizontales o en retícula, estampados diversos o con aplicaciones tipo mamelones o cordones (una descripción más completa puede encontrarse en Dorrego Martínez y Rubiero Da Pena 1998).

Las formas asociadas a esta CTO, especialmente los característicos bordes facetados (96-1009; 96-892 


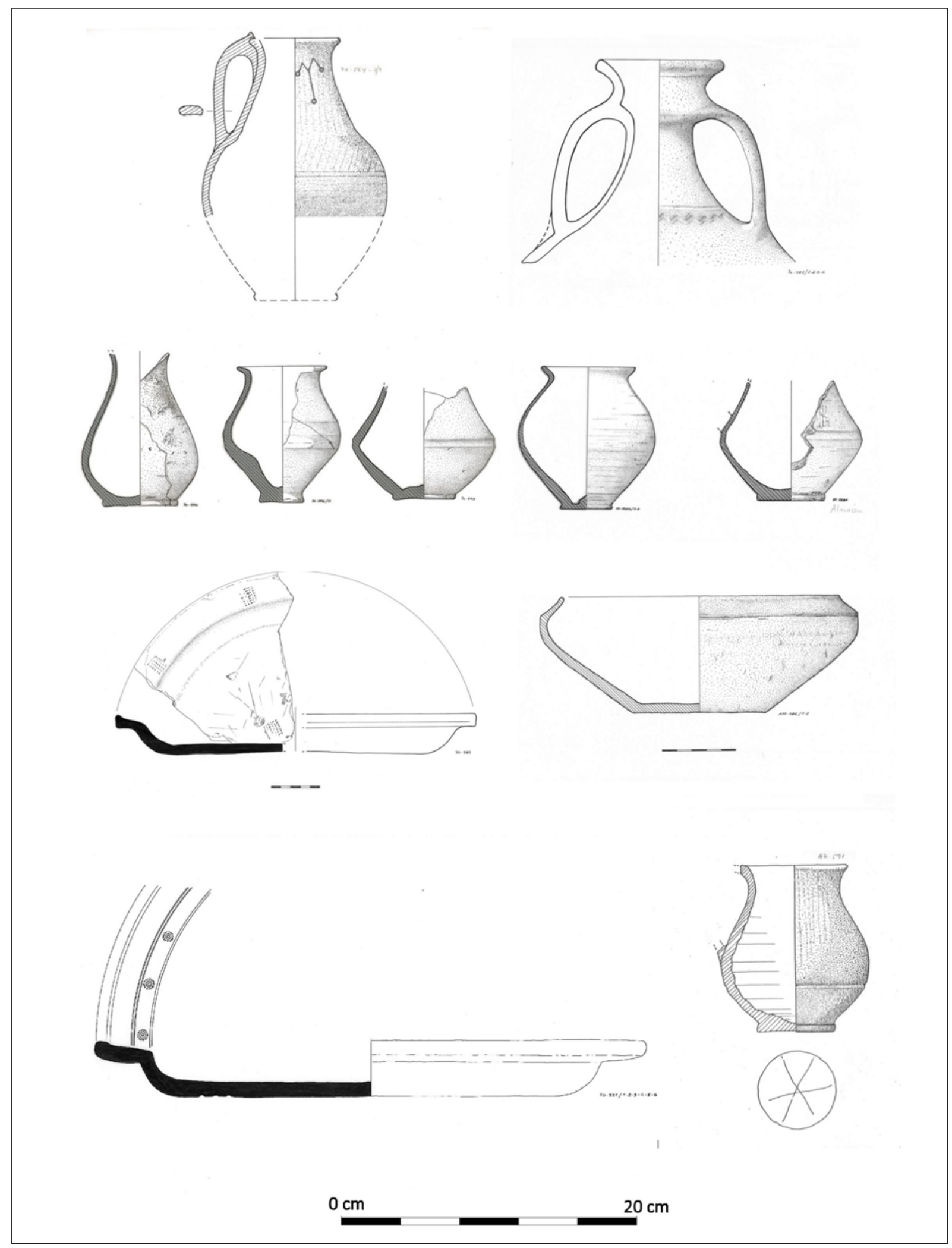

Figura 4. Cerámicas tardías de Viladonga. Dibujos del Museo del Castro de Viladonga. 
y 96-103), nos remitirían fundamentalmente a un horizonte de la Segunda Edad de Hierro (Marín Suárez 2012) y más concretamente, en el contexto de la cuarta o tercera centuria a. C. (Dorrego Martínez y Rubiero Da Pena 1998: 26), que marcaría los momentos de ocupación más tempranas del castro. Estas cadenas tecnológicas tendrían, sin embargo, una pervivencia larga en el tiempo, que llegaría probablemente hasta el cambio de era, sustituidas progresivamente por los ciclos de la "cerámica común romana", muy característicos por su fabricación mediante torneados rápidos y el masivo uso de cocciones oxidantes. Los paralelos de estas producciones prehistóricas de Viladonga son variados, como mostrarían los conjuntos de yacimientos geográfica y cronológicamente similares como Campa Torres (Gijón) (Maya y Cuesta Toribio 2001) o Formigueiros (Samos, Lugo) (Rey Castiñeira 2010), datados en momentos similares y dentro del "área cantábrica” definida por A. GonzálezRuibal (González Ruibal 2006-2007: 459-463).

Dentro del conjunto de cerámicas prehistóricas llamó la atención un subgrupo de producciones que, si bien mantenían las características tecnológicas y formales definidas para esta CTO, presentaban marcas de rotación, generalmente de rotaciones lentas pero que adquirían en algunos casos una significativa regularidad. A modo de hipótesis, asociamos este conjunto con producciones de "tradición indígena", esto es, producciones realizadas con las cadenas tecnológicas definidas para la Segunda Edad de Hierro pero en momentos posteriores a la conquista romana, momento de introducción de los sistemas mecánicos de torneado en los contextos del noroeste peninsular (González Ruibal 2006-2007: 496). De hecho, la mayoría de estas producciones se encontraba en asociación estratigráfica con cerámicas engobadas, lo que indicaría que este tipo de producciones se podrían datar de forma genérica en el cambio de era, marcando un momento de transición entre las producciones "indígenas" y las propiamente asociadas al Imperio (Alcorta Irastorza 2001: 50 y ss.). Este fenómeno está bien documentado en otros contextos, y se observa de forma muy clara en el repertorio cerámico de Chao Samartín (Hevia González et al. 1999) así como en Formigueiros (Fernández Pereiro et al. 2017; Rey Castiñeira 2010).

\subsubsection{El final de la secuencia cerámica: las} producciones de épocas romana y post-romana

En el otro extremo de la horquilla cronológica, las producciones más modernas documentadas, descartando algunos escasos fragmentos asociados a las ocupaciones contemporáneas, se relacionarían con producciones imitadoras de la sigillata, denominadas genéricamente CIS (Juan Tovar 2012b), imitaciones de cerámica gálica en cocciones reductoras o imitaciones de producciones africanas tardías, así como algunas cadenas tecnológicas en cocciones reductoras y mixtas de pastas depuradas (denominadas como TRC y TRA) que nos remiten, grosso modo, a un horizonte seguro de la quinta centuria. Concretamente, algunas de las producciones y formas expuestas en la colección permanente del museo del castro (Figs. 4 y 5), como por ejemplo los grandes platos con decoración bruñida en producciones tipo CIS, imitaciones grises o cerámica engobada, remiten a contextos del tercer cuarto de la quinta centuria, como en Navasangil (Solosancho, Ávila) o Castro Ventosa (Cacabelos/Pieros, León) (Tejerizo García y Vigil-Escalera Guirado 2017). Especialmente interesantes para analizar estos momentos tardíos son las formas de cuencos imitadoras de formas sudgálicas tardías en cocción reductora. En concreto, el cuenco 07-574, que remitiría a la forma 5 de Rigoir, datada genéricamente entre muy finales del s. IV d. C. hasta finales del siglo VI d. C. (Raynaud 1993; Rigoir 1968) pero que creemos más encuadrada en la segunda mitad del siglo V d. C. dentro del conjunto de Viladonga, con paralelos en yacimientos como El Castillón (Santa Eulalia de Tábara, Zamora) (Sastre Blanco et al. 2014), Braga (Fernández Fernández y Bartolomé Abraira 2016: 76) o similares a las formas 6 u 11 reconocidas en Astorga (Paz Peralta 2013), todas datadas en la segunda mitad del siglo V d. C. (fig. 5).

Algunas formas podrían remitir a contextos de los primeros momentos del siglo VI d. C. Este sería el caso de las producciones de ollas o jarritas a torno rápido de cerámica reductora con pastas semidepuradas (cadenas TRB y TRC), con decoración mediante ondas incisas en el galbo (07-665) o en el labio (07-526), o bruñida tanto en líneas verticales (07-791 y 08-154), líneas verticales combinada con bandas cóncavas (96-1121 y 1122) o en retícula. Producciones que nos acercarían a contextos que podrían estar insertos en la sexta centuria, similar a algunos yacimientos del centro peninsular como Senovilla (Olmedo, Valladolid) o Ladera de los Prados (Aguasal, Valladolid) (Tejerizo García 2016). Igualmente, la presencia de fondos con pie resaltado en cadenas tecnológicas de cocción reductora a torno rápido con pastas semidepuradas (por ejemplo 03-340 o 2016/00844) podría indicar cronologías de finales de la quinta o muy inicios de la sexta centuria (Vigil-Escalera 2013) y que también han sido localizados en sitios 


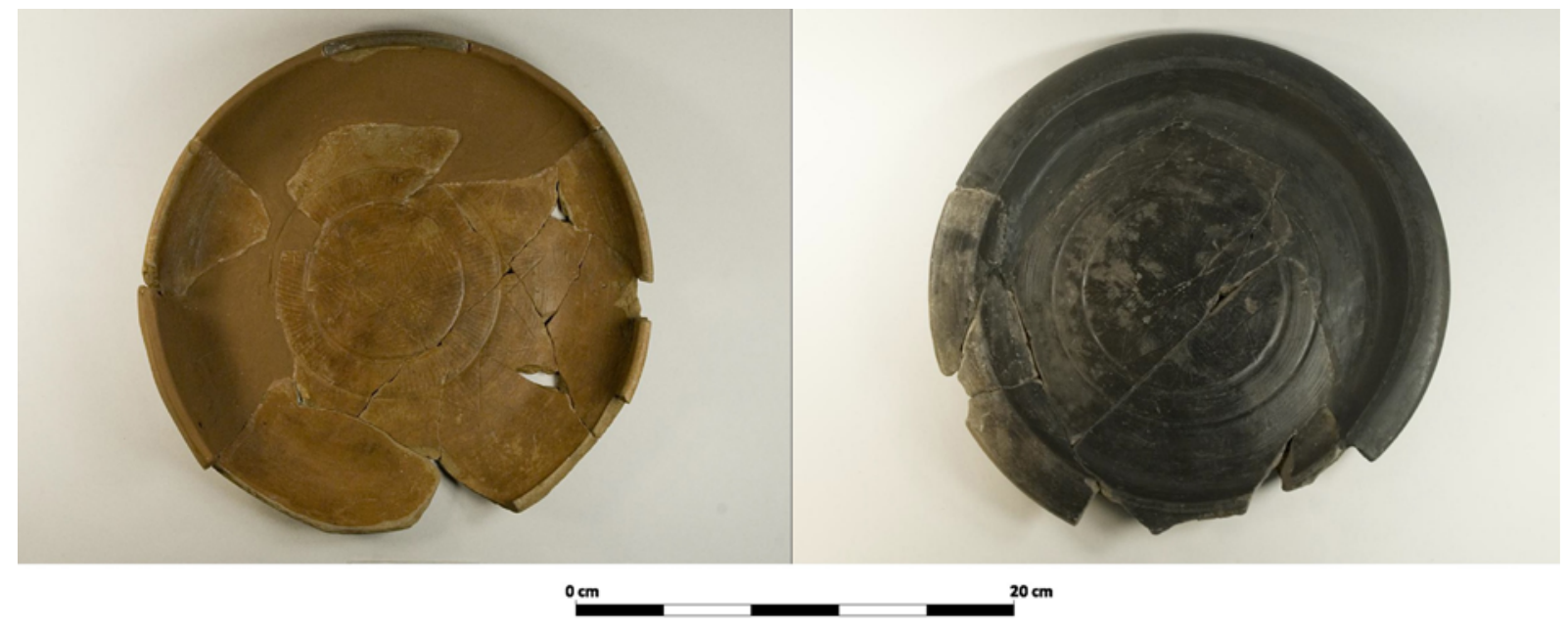

Figura 5. Platos con decoración bruñida tardíos de Viladonga. Fotografías cedidas por el Museo del Castro de Viladonga.

del entorno, como Elviña (Bello Diéguez 2018). Finalmente, la presencia de algunas formas carenadas podrían indicar también la ocupación del sitio durante los primeros momentos del siglo VI d. C.; concretamente, la forma $07-665$, reductora a torno rápido con decoración de ondas incisas sobre una carena, remite a formas conocidas en el centro peninsular en yacimientos como Navasangil y datadas entre mediados del siglo V e inicios del VI d. C.(Tejerizo García y Vigil-Escalera Guirado 2017) (figs. 6 y 7). Esta cronología de abandono del asentamiento a inicios de la sexta centuria mostrada por la cerámica es acorde a las propuestas de la mayoría de los autores (Rodriguez Resino 2006).

M.R. Lovelle y J.L. Quiroga mencionan la posible presencia de materiales y estructuras que podrían señalar cronologías de ocupación posteriores al siglo VI d. C. (Lovelle y López Quiroga 2000: 63-64). Sin embargo, en la revisión realizada no se encontraron materiales ni conjuntos cerámicos que permitan extender la cronología de ocupación del sitio más allá de mediados de la sexta centuria - sin descartar que pudieran documentarse en otras campañas pero que hasta el momento no se hayan reconocido. Algunos datos permiten reforzar esta hipótesis de un abandono a inicios del siglo VI d.C.: la significativa cantidad de cerámica estampillada en producciones imitadoras de sigillata en los contextos de amortización de las construcciones que marcarían un momento ante quem de abandono de dichos edificios a mediados de la sexta centuria (Juan Tovar 2012a); la ausencia de producciones importadas que superen la barrera de mediados de la sexta centuria (Fernández Fernández y Bartolomé Abraira 2016); o la escasa presencia de producciones características de los conjuntos de la segunda mitad del siglo VI y VII d. C., como serían las cerámicas grises bruñidas de gran calidad (TRA), una mayor presencia de cuencos carenados en producciones de menor calidad o una significativa presencia en los contextos estratigráficos tardíos de cerámica realizada a torno lento (Vigil-Escalera 2003). De esta manera, y a tenor de los conjuntos cerámicos analizados, no existen contextos estratigráficos en el castro que puedan ser datados en un momento posterior a inicios de la sexta centuria.

\subsubsection{El hiato en la secuencia: las producciones de sigillata y engobadas.}

Por lo visto hasta ahora, en una primera aproximación se observan dos grandes momentos de ocupación del castro. Una primera se situaría en un momento avanzado de la Edad de Hierro y que alcanzaría todo el s. I d. C. Una segunda relacionada con la última ocupación del yacimiento que podemos situar, tentativamente, en un claro siglo quinto y, muy posiblemente, los primeros compases del siglo VI d. C. La duda se presenta entonces para los siglos centrales de esta secuencia y, más específicamente, los siglos II-IV d. C. Para plantear una solución a este problema, hay que analizar varias cuestiones en relación al conjunto vascular.

En primer lugar es relevante hacer mención a la Terra Sigillata presente en el conjunto, como uno de los elementos datantes más significativos de este período. En este sentido, tomaremos también en consideración la publicación específica de Caamaño y López Rodríguez 


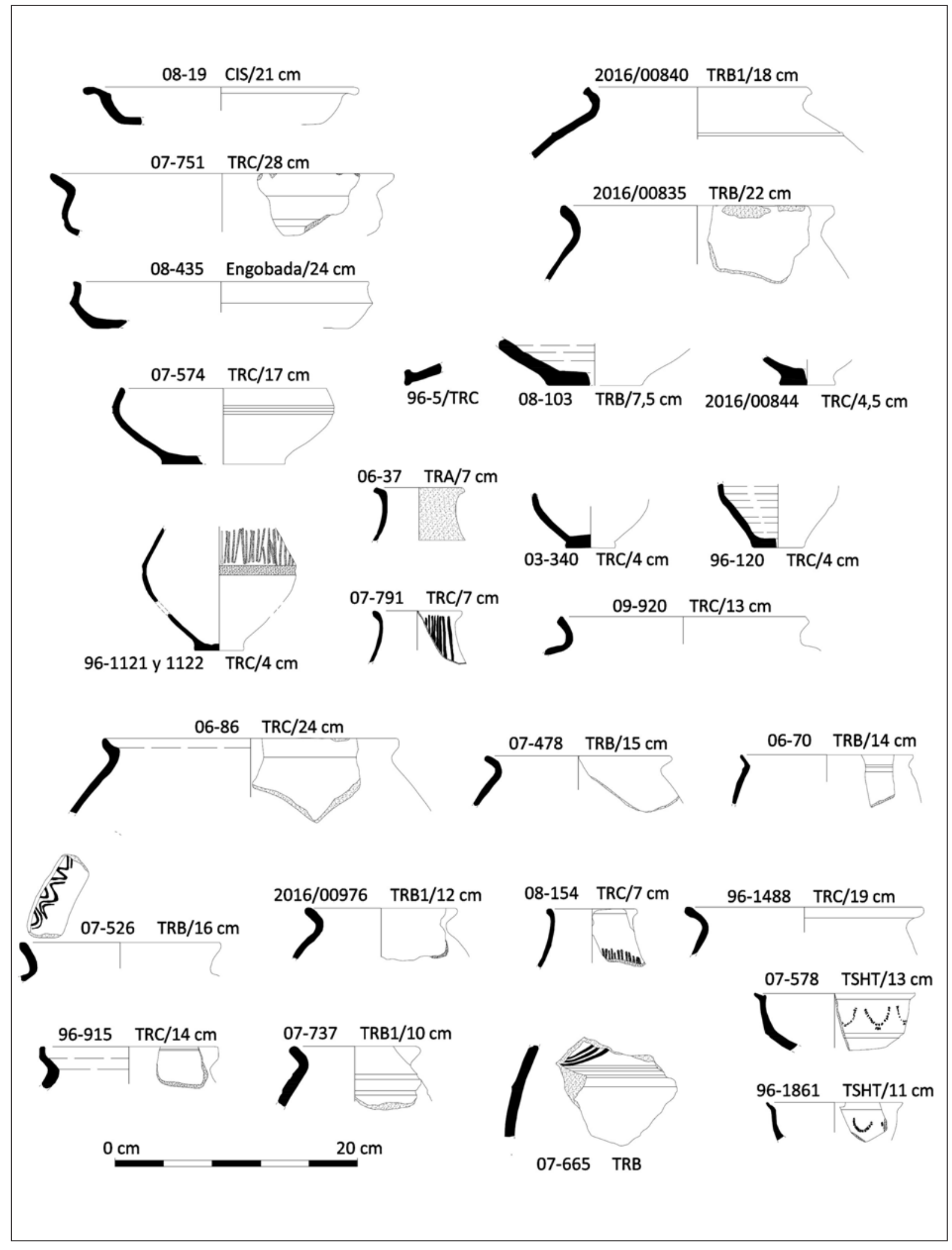

Figura 6. Cerámica de Viladonga (II). Dibujos de los autores. 


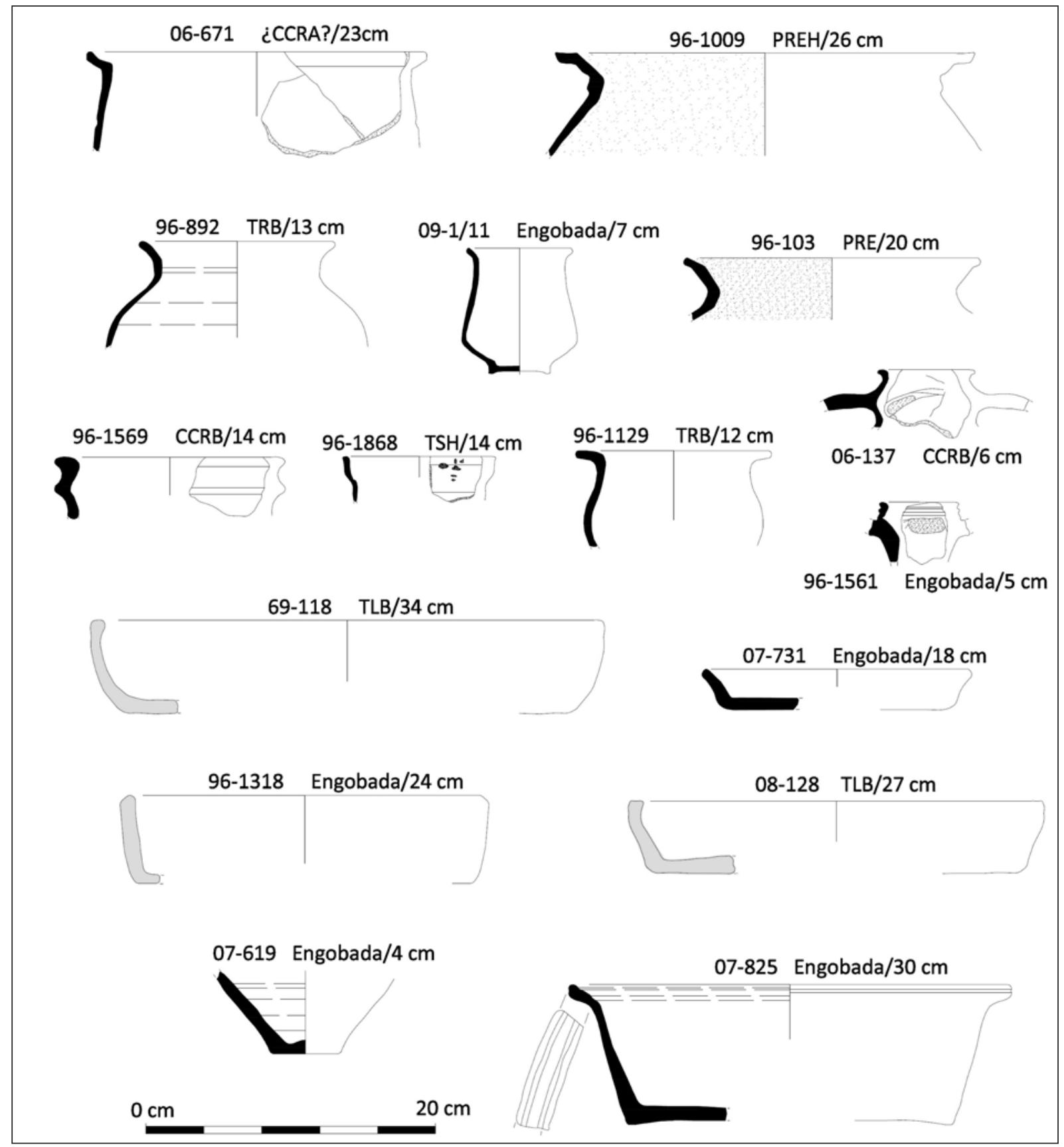

Figura 7. Cerámica de Viladonga (III). Dibujos de los autores.

en el que se analizaron unos 80 fragmentos de sigillata. Este conjunto fue datado por estos autores, sin solución de continuidad, "entre la segunda mitad del siglo I hasta el fin del Imperio Romano” (Caamaño Gesto y López Rodríguez 1984: 167). Sin embargo, a partir de los avances en el estudio de la sigillata desde que se hizo aquel pionero estudio, sugerimos la existencia de una cesura de ocupación entre los siglos II d. C. y la mayor parte del siglo IV d. C. (fig. 8).

En este conjunto de sigillatas se han distinguido dos grandes grupos: las producciones altoimperiales -tanto gálicas como hispanas- $\mathrm{y}$, por otro lado, las producciones de Terra Sigillata Hispánica Tardía, bien reconocibles por sus características pastas y motivos decorativos. 


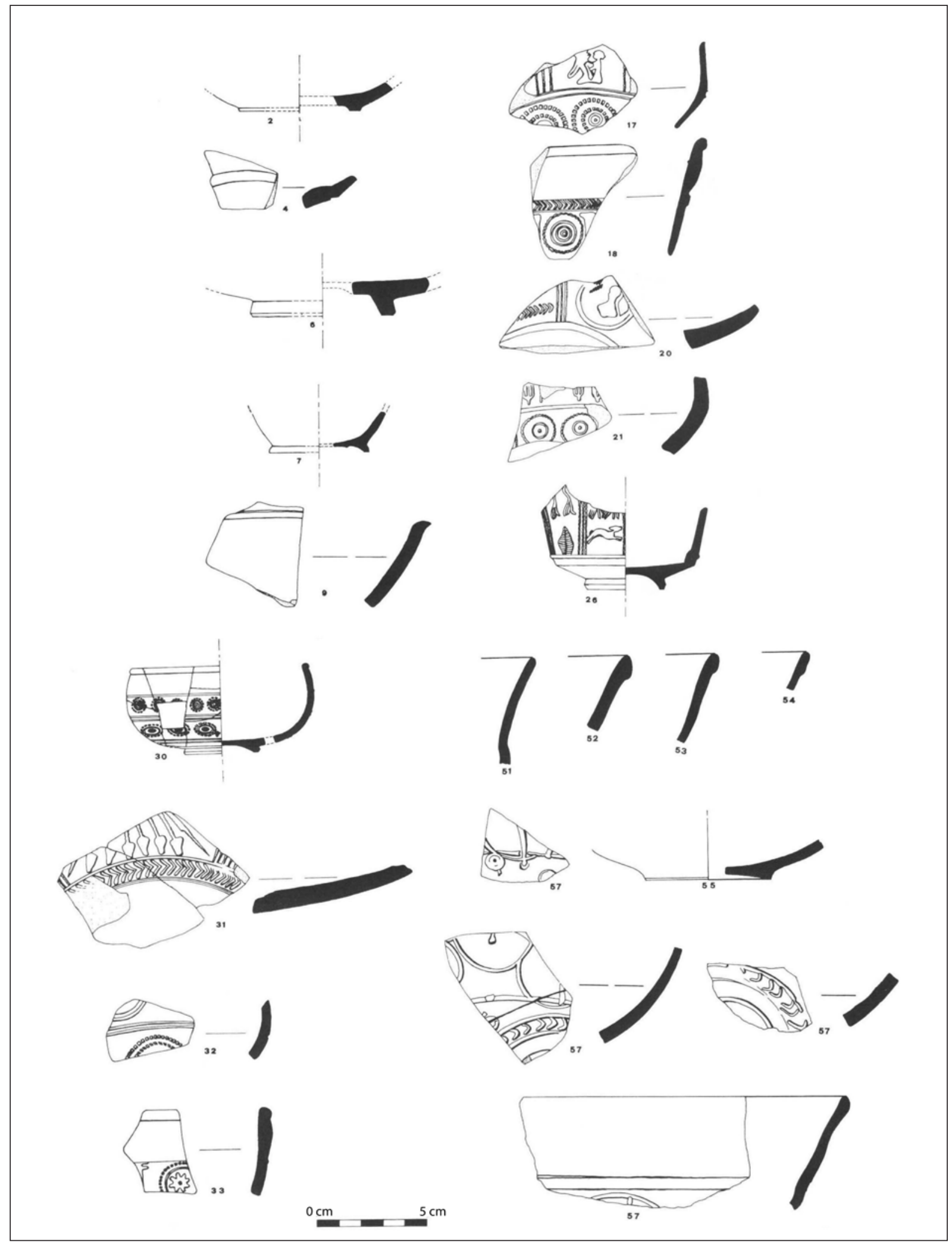

Figura 8. Sigillatas de Villadonga (Caamaño Gesto y López Rodríguez, 1984). 
En el primer grupo, destaca un conjunto de materiales publicados entre las que se observaron algunas formas hispanas imitadoras de Drag. 27, Drag. 29, Drag. 30 y Drag. 35 (Caamaño Gesto y López Rodríguez 1984: 158-163). Si bien algunas de estas formas podrían, en tanto que formas, alcanzar el siglo III d. C., como ocurre con la forma 29 (Bustamante Álvarez 2013-2014), el análisis de conjunto señalaría una datación no más allá del segundo cuarto del s. II d. C. En particular, cabe destacar una forma 30 decorada a base de metopas con motivos animales (Caamaño Gesto y López Rodríguez 1984: 160-161; fig. 162 forma 126) que se puede datar entre finales del siglo I d. C. y, como mucho, mediados del siglo II d. C. (Bustamante Álvarez 2013-2014: 569; Mezquíriz 1961: 199-200). Cronologías similares se manejan para otras formas características presentes en el conjunto del castro de Viladonga, como la forma 35 (Bustamante Álvarez 2013-2014; Mezquíriz 1961: 63-66). En nuestra opinión, esta cronología final marcaría, así mismo, el final de este grupo de sigillatas y de la primera gran fase de ocupación en el castro.

Por su parte, en el conjunto de sigillatas tardías se han documentado tres tipos distintos. El primer conjunto, más numeroso, de sigillatas lisas, la mayoría de ellas bajo la forma tardía del cuenco 37. En segundo lugar, un conjunto de sigillatas tardías decoradas a molde, fundamentalmente a través de círculos y medias lunas típicas del denominado "segundo estilo" de Mayet o grupo 2A/B de Vigil-Escalera (Vigil-Escalera 2015: 290-291 y 294-297). Según la revisión realizada por este último autor, estas producciones deberían ser datadas ya a partir del último cuarto del siglo IV d.C. (Vigil-Escalera 2015: 104). Finalmente, un mínimo conjunto de piezas (4 fragmentos), con decoración estampillada en el galbo en formas 37 tardías formando semicírculos (07-578 y 96-1861), dentro del grupo 4B de Vigil-Escalera y que se encuadran dentro de la primera mitad de la quinta centuria (Vigil-Escalera 2015: 299-300). Por lo tanto, el conjunto de sigillatas tardías señalaría una cronología de ocupación de Viladonga a partir de muy finales del siglo IV d. C., quizá ya dentro de la quinta centuria.

El aspecto más llamativo del conjunto de producciones de sigillata es, sin embargo, su escasa presencia relativa, como un factor esencial para la datación de los contextos de este período (Vigil-Escalera 2015). Estas representan en total menos del 3\% de los fragmentos y $1 \%$ del peso del conjunto analizado. Estas cantidades ya deberían poner en duda una ocupación del sitio entre, al menos, la mayor parte de la segunda centuria y la primera mitad del siglo IV d. C., dado que los contextos en estas centurias se caracterizan, precisamente, por una presencia mucho más significativa en términos cuantitativos de esta cerámica (Fernández Fernández et al. 2018; Paz Peralta 1991). Particularmente, destaca la ausencia de un conjunto mucho más voluminoso de sigillatas hispánicas lisas, que serían un rasgo característico de los conjuntos del s. III y primera mitad del s. IV d. C. (Vigil-Escalera 2015).

Otro conjunto de cerámicas relevantes para la datación de los contextos serían las cerámicas engobadas, como una de las producciones más significativas del noroeste peninsular. Estas producciones están estrechamente relacionadas con la ciudad de Lugo, donde fueron producidas de forma masiva ya desde el siglo I d. C. hasta, al menos, la quinta centuria (Alcorta Irastorza 2001). En Viladonga, existe un significativo número de cerámicas con engobes en el conjunto analizado $(9,34 \%$ de los fragmentos y $9,51 \%$ del peso) tanto en formas abiertas (cuencos, platos, fuentes...) como cerradas (jarritas, ollas, vasos...). De estas destacan algunos casos individuales del conjunto analizado. En primer lugar, la forma 09-1/11, un vasito con pie de cuerpo alargado y labio exvasado que correspondería a la forma V2 de Alcorta y que ha sido documentada en los estratos altoimperiales de Lugo anteriores al s. III d. C. (Alcorta Irastorza 2001: 265-270; Alcorta Irastorza y Bartolomé Abraira 2012: 716) y que corresponderían a la primera fase de ocupación del sitio. En segundo lugar, el fragmento $08-435$, un cuenco de boca ancha y cuerpo poco desarrollado con una significativa carena y labio ligeramente exvasado, que remitiría a formas tardoimperiales del siglo IV o V d. C., (Alcorta Irastorza y Bartolomé Abraira 2012: 715-721) si bien habría que incluirlo fundamentalmente en la quinta centuria, siguiendo el análisis de L.C. Juan Tovar (Juan Tovar 2012b: 28). Igualmente, la forma 07-825 correspondería al tipo EP6 de Alcorta, una fuente de borde moldurado muy común en los contextos tardíos de la ciudad de Lugo (Alcorta Irastorza 2001).

Cabe destacar, por último, dos piezas engobadas analizadas de la exposición permanente del Museo del Castro de Viladonga. La primera es un cuenco de cuerpo globular, labio exvasado vuelto y pie ligeramente desarrollado, muy similar al tipo 18T de Alcorta y Bartolomé (Alcorta Irastorza y Bartolomé Abraira 2012: 719; Figura 713.716). La segunda forma corresponde a una gran fuente con labio vuelto y moldurado, con decoración incisa interna, siendo engobada toda la forma. Se trata de una fuente de imitación de formas de la sigillata y que formarían parte de un servicio de mesa, asociada a la forma I59 de los autores mencionados, que 
la relacionarían con "producciones similares de $\mathrm{Bra}$ cara Augusta" (Alcorta Irastorza y Bartolomé Abraira 2012: 719). Ambas formas se sitúan cronológicamente en una horquilla entre finales del siglo IV y mitad del siglo $\mathrm{V}$ d.C.

Tanto las producciones de sigillata como las producciones engobadas parecen sugerir ocupaciones efectivas del sitio en dos momentos cronológicos distintos: en primer lugar, una ocupación situada fundamentalmente en la primera centuria y, quizá, los inicios de la segunda; y, en segundo lugar, una ocupación datada en la segunda mitad del siglo IV y la primera mitad del siglo V d.C. Por el contrario, no existen evidencias de conjuntos cerámicos ni estratigrafías asociadas para la horquilla entre la segunda mitad del siglo II y la primera mitad del siglo IV d.C., reforzando la hipótesis de un hiato en la ocupación del sitio en este momento. Para profundizar en esta hipótesis, analizaremos ahora otros materiales que puedan ofrecer alguna información cronológica adicional.

\subsection{La cultura material del Castro de Viladonga: vidrios y monedas}

Las reiteradas intervenciones sobre el castro han proporcionado una abundante cantidad de materiales arqueológicos y que, evidentemente, van mucho más allá del conjunto cerámico, ya de por sí significativo. Sobre el resto de la cultura material del sitio se han realizado algunos trabajos monográficos, como ocurre con los anillos (Durán Fuentes y Fernández Vázquez 1999), las fíbulas (Lage Pillado 2004) o los apliques de bronce (Arias Vilas y Durán Fuentes 1997). La mayoría de ellos, por su propia naturaleza como objeto arqueológico -con períodos de uso y amortización muy amplios que dificultan su datación dentro de los contextos arqueológicos- y por estar generalmente descontextualizados ya que provienen en su mayoría de las excavaciones antiguas, son poco útiles a la hora de proporcionar datos para la secuenciación cronológica del yacimiento, objeto del presente estudio.

Mención particular merecen, sin embargo, tres tipos de materiales que ofrecen relevantes datos para los objetivos del presente trabajo: los vidrios, el repertorio numismático.

El significativo conjunto de vidrios de Viladonga fue objeto de una publicación específica (Da Cruz 2007), si bien sólo tuvo en cuenta aquellos materiales exhumados en las excavaciones antiguas y, por lo tanto, ausentes de un contexto estratigráfico. Sin embargo, dentro del conjunto de vidrios de Viladonga se localizan formas y tipos singulares que permiten añadir algunos datos para la secuenciación del yacimiento. Siguiendo el análisis de M. da Cruz se pueden distinguir dos grandes grupos. Por un lado, se documentan vidrios correspondientes a la fase contemporánea a la llegada de Roma, en torno al siglo I d.C. De este grupo destaca el conocido cuenco de costillas o taza canelada, cuya cronología se encuadra a finales de esta centuria. Igualmente se encuentran algunos tipos de ungüentarios comunes de este período, o bases de vidrio tipo Isings 50 (Da Cruz 2007: 15; Isings 1957).

Con todo, el grueso de los vidrios exhumados en Viladonga puede ser encuadrado en época bajoimperial, concretamente a partir del siglo IV d.C. (fig. 9) De este material destacan algunas producciones como el cuenco semiesférico con decoración de cabujones con paralelos en la forma 96 de Isings que De la Cruz fecha en torno al siglo V (Da Cruz 2007). Este tipo de cuencos con cabujones se han reconocido en algunas necrópolis postimperiales en el ámbito del Duero, como Roda de Eresma, y datadas a mediados de la quinta centuria (Molinero Pérez 1971; Vigil-Escalera 2015). No menos importante es la botella con depósito cilíndrico, de boca abocinada y con asa, de un vidrio oscuro y transparente (Da Cruz 2007: 52; fig. 56), Tipo IA variante 1 de A. Fuentes y con un paralelo muy similar en la necrópolis de Fuentespreadas, igualmente datada a mediados del s. V d.C. (Fuentes Domínguez 1990: 179).

Este potencial hiato en las producciones de vidrio altoimperiales y bajoimperiales ya fue puesto de relieve por M. da Cruz, que concluía su estudio afirmando que "A existir um hiato parece-nos mais provável que este se inicie precisamente no final do período Flávio, pelos finais do séc. I e termine já bem entrados no séc. III”, observando la ausencia de materiales de los siglos II y III d. C. y finalizando la secuencia en la quinta centuria ante la ausencia de producciones de vidrio del s. VI d. C. (Da Cruz 2007: 22).

Por su parte, el importante numerario exhumado en el yacimiento es uno de los aspectos más destacados, llegando posiblemente a las 2500 monedas, incluyendo las últimas campañas (Durán Fuentes 2009). Como conjunto, las monedas documentadas en Viladonga cubren un amplio espectro desde el cambio de era hasta muy finales del s. IV. Un inventario de 183 monedas que pudieron ser identificadas y analizadas por M.C. Durán arrojaba los datos reflejados en la figura 10 (fig. 10).

En esta figura se refleja perfectamente la masiva presencia de monedas de la cuarta centuria, que 


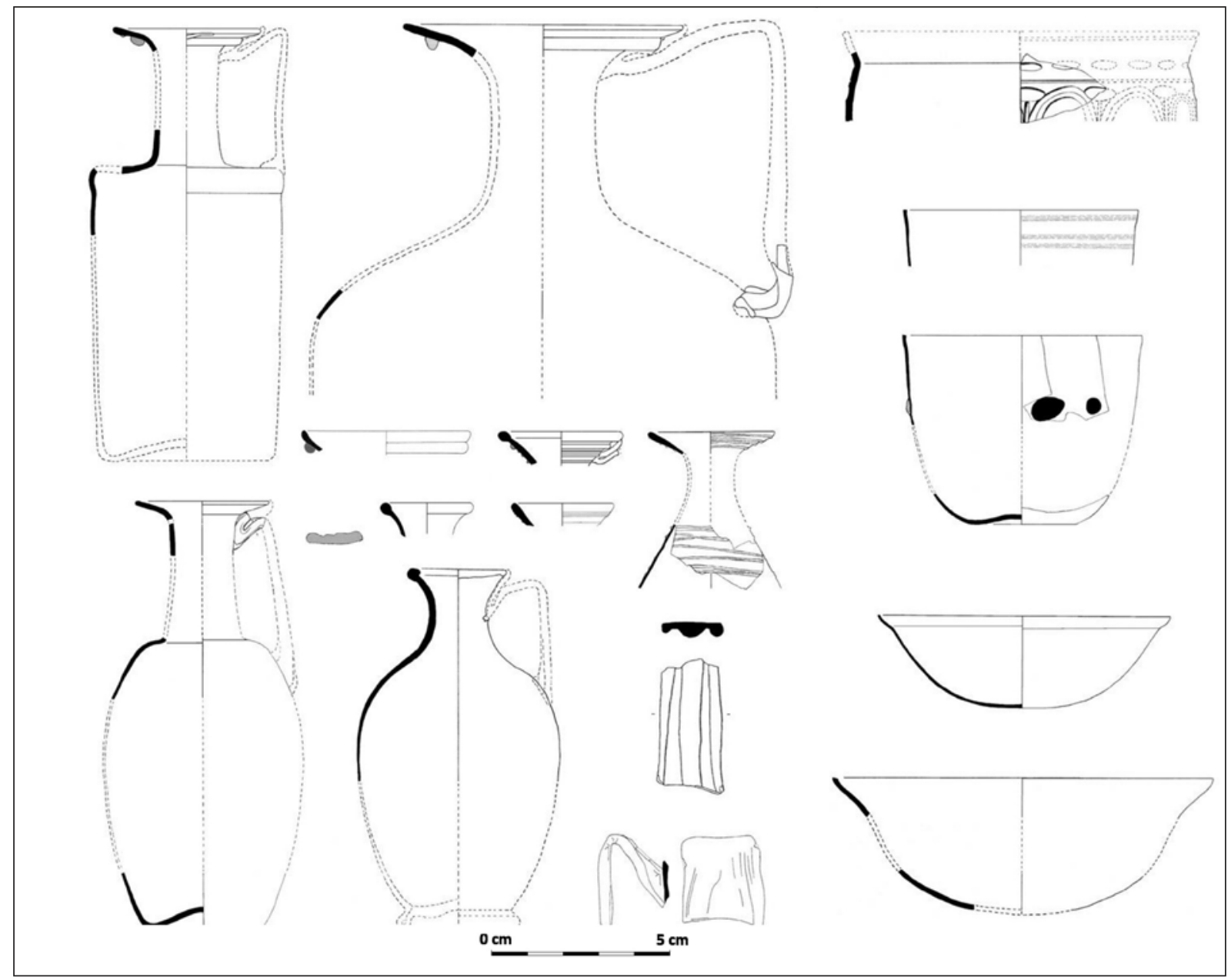

Figura 9. Vidrios tardoimperiales en Viladonga (Da Cruz, 2007).

superan el $87 \%$ del conjunto analizado. Este conjunto incluye un importante elenco de emisiones desde las familias constantinianas hasta dos ejemplares de sólidos áureos acuñados por Teodosio en nombre de su hijo Arcadio y asociado a Honorio como las monedas más recientes y datadas entre 394-395.

La moneda republicana y altoimperial, en cambio, supone únicamente un $9 \%$ del total identificado. Las emisiones de los siglos de transición del II al III d.C. tampoco son especialmente numerosas, menores al $4 \%$. Algunos ejemplares de Trajano (98-117) y Antonino Pío (138-161) cubrirían la primera mitad del siglo II d. C. y algunas monedas de Alejandro Severo (222235), Gordiano II (238), Valeriano I (253-260), Claudio II (268-270) y tres antoninianos de bronce (268-270) representarían las emisiones del siglo III d. C. El hecho de que la moneda altoimperial más moderna sea de Antonino Pío, acuñada entre el 140-153 d. C. (Durán Fuentes
2000: 19) reforzaría el argumento defendido a partir del análisis cerámico y del vidrio de un abandono del sitio en la primera mitad del siglo II d. C. Por su parte, la presencia de monedas de la tercera centuria ha sido uno de los argumentos principales para afirmar una ocupación del sitio datada, post quem, durante este período (Arias Vilas 1993, 1996). Sin embargo, la escasa presencia de monedas de este siglo (reducidas a los ejemplares señalados), su hallazgo descontextualizado y el análisis previamente realizado sobre la cerámica y el vidrio permitirían sugerir la hipótesis de que esta moneda fue reutilizada en momentos posteriores a su fabricación y amortizada ya durante el intervalo entre la cuarta y la quinta centuria. De hecho, la reutilización de moneda de cronologías previas en contextos de la cuarta y quinta centuria es un fenómeno especialmente común y que no supondría una excepción (King 2013). Dicho de otra manera, la presencia de moneda del siglo III d.C. 


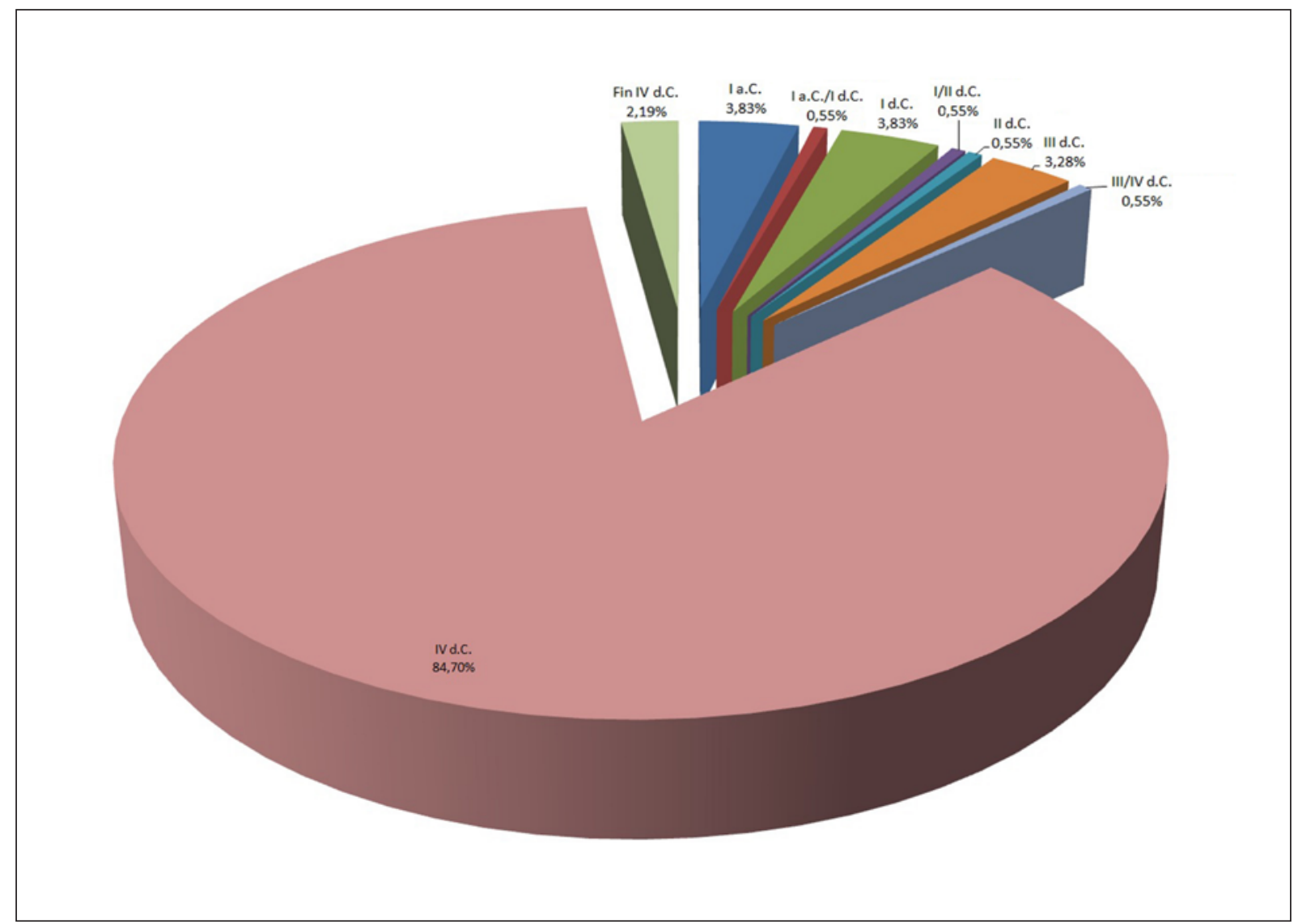

Figura 10. Distribución cronológica de las monedas identificadas en Viladonga (a partir de Durán Fuentes, 2009).

en Viladonga mostraría fundamentalmente su reutilización en contextos cronológicamente posteriores y no una ocupación efectiva del sitio durante este período. Este argumento se verá reforzado por el análisis estratigráfico particular del apartado 3.5. en el que se ha podido contextualizar un pequeño tesorillo.

\subsection{Las dataciones radiocarbónicas}

Al contrario que en otros contextos similares del centro y del norte peninsular, Viladonga cuenta con una pequeña batería de dataciones publicadas especialmente interesante para analizar la secuencia de ocupación (Vigil-Escalera y Tejerizo García 2014). Hasta el momento se han publicado un total de seis, cuatro de ellas provenientes de las campañas de 1988 y 1989 (Arias Vilas y Fábregas Valcarce 2003) y otras dos de la campaña de 1996, presentadas en el informe correspondiente depositado en el Museo de Viladonga. Es importante destacar que estas dataciones no responden a un intento de secuenciar las fases finales del sitio, sino a los objetivos específicos de esas campaña, más vinculadas con la secuenciación de los primeros momentos de ocupación. A pesar de todo, y con el objetivo no sólo de proponer una secuencia lo más completa posible del sitio sino también de exponer todos los datos disponibles a tal efecto, parece interesante analizar este lote de dataciones en su conjunto. En la tabla 3 se resumen sus características (fig. 11).

Como se observa, existen dos grandes grupos de dataciones. Aquellas que hacen referencia al intervalo entre el s. IV a. C. y el s. I o incluso II d. C. y CSIC-1220, centrada entre los siglos V-VII d. C. Tres de ellas (CSIC861, CSIC-862 y CSIC-938) se muestrearon en contextos similares, asociados a los posibles hogares de algunas estructuras domésticas localizadas junto a la muralla este del castro. Las tres muestran rangos muy similares y marcarían una fecha post quem de ocupación de esas estructuras domésticas entre el siglo III a. C. -quizá en sus últimos momentos-e inicios del siglo II d. C. Como se especifica en la publicación, los contextos se asociaban a cerámica 
Tabla 3. Características de las fechas radiocarbónicas realizadas en Viladonga.

\begin{tabular}{|c|c|c|l|c|c|}
\hline Campaña & No Ref. & Material datado & \multicolumn{1}{|c|}{ Contexto } & Datación & Calibración (2 sigma) \\
\hline $1988-1989$ & CSIC-896 & Material óseo & $\begin{array}{l}\text { Relleno interior de la mura- } \\
\text { lla principal en la zona este del } \\
\text { castro }\end{array}$ & $2190 \pm 60 \mathrm{BP}$ & $391-93 \mathrm{calBC}$ \\
\hline $1988-1989$ & CSIC-861 & Carbón vegetal & $\begin{array}{l}\text { Hogar situada cerca de la mura- } \\
\text { lla este. Asociada a material pre- } \\
\text { histórico. }\end{array}$ & $2040 \pm 50 \mathrm{BP}$ & 179 calBC-63calAD \\
\hline $1988-1989$ & CSIC-862 & Carbón vegetal & $\begin{array}{l}\text { Espacio, posible hogar, vincu- } \\
\text { lado a estructuras domésticas en } \\
\text { la zona este del castro. Asociada } \\
\text { a material prehistórico. }\end{array}$ & $2040 \pm 60 \mathrm{BP}$ & $202 \mathrm{calBC}-80 \mathrm{calAD}$ \\
\hline $1988-1989$ & CSIC-938 & Carbón vegetal & $\begin{array}{l}\text { Espacio, posible hogar, vincu- } \\
\text { lado a estructuras domésticas en } \\
\text { la zona este del castro. Asociada } \\
\text { a material prehistórico. }\end{array}$ & $2040 \pm 25 \mathrm{BP}$ & $\begin{array}{c}160-134 \mathrm{calBC}(4,5 \%) \\
116 \mathrm{calBC}-25 \mathrm{calAD} \\
(90,9 \%)\end{array}$ \\
\hline 1996 & CSIC-1321 & Carbón vegetal & $\begin{array}{l}\text { VD.2.96.9B (por debajo estruc- } \\
\text { tura } 1 \text { de antecroa oeste) }\end{array}$ & $2165 \pm 26 \mathrm{BP}$ & $\begin{array}{l}358-279 \mathrm{calBC}(46,8 \%) \\
259-156 \mathrm{calBC}(45,8 \%) \\
135-116 \mathrm{calBC}(2,7 \%)\end{array}$ \\
\hline 1996 & CSIC-1220 & Carbón vegetal & $\begin{array}{l}\text { VD.2.96.12 (trozo de madera en } \\
\text { el camino de entrada) }\end{array}$ & $1521 \pm 34 \mathrm{BP}$ & 427-609calAD \\
\hline
\end{tabular}

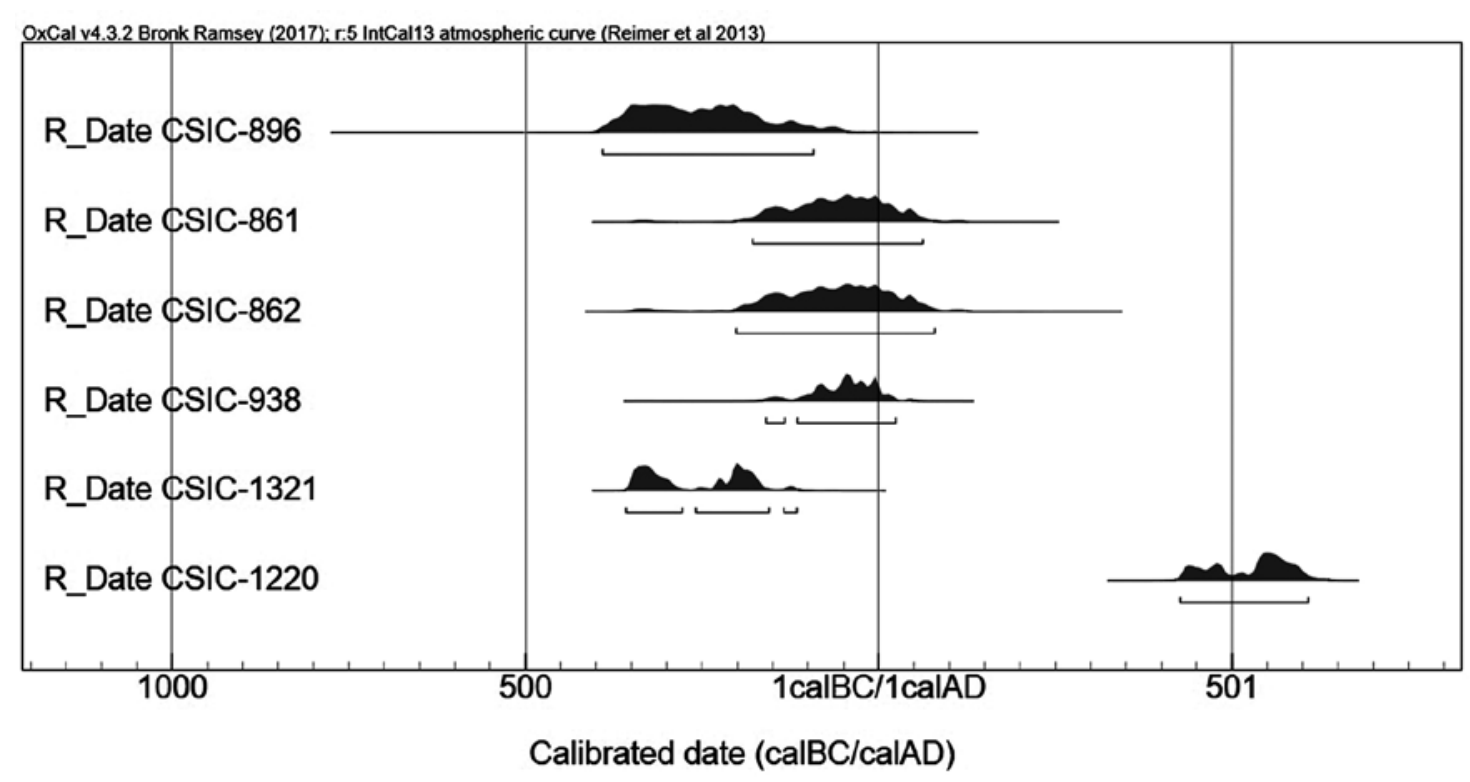

Figura 11. Dataciones calibradas de Viladonga.

claramente prehistórica, "fragmentos de cerámica común de tradición castrexa, moi ruín e esnaquizada, dalgunhas pezas de bronce tamén fragmentadas e pouco definidas" (Arias Vilas y Fábregas Valcarce 2003: 197), sin mención a la aparición de sigillatas o cerámicas asociadas a los ciclos de común romana. Esto invitaría a pensar en unas cronologías más centradas entre el s. III a. C. y el cambio de era para la datación de estos contextos como ya 


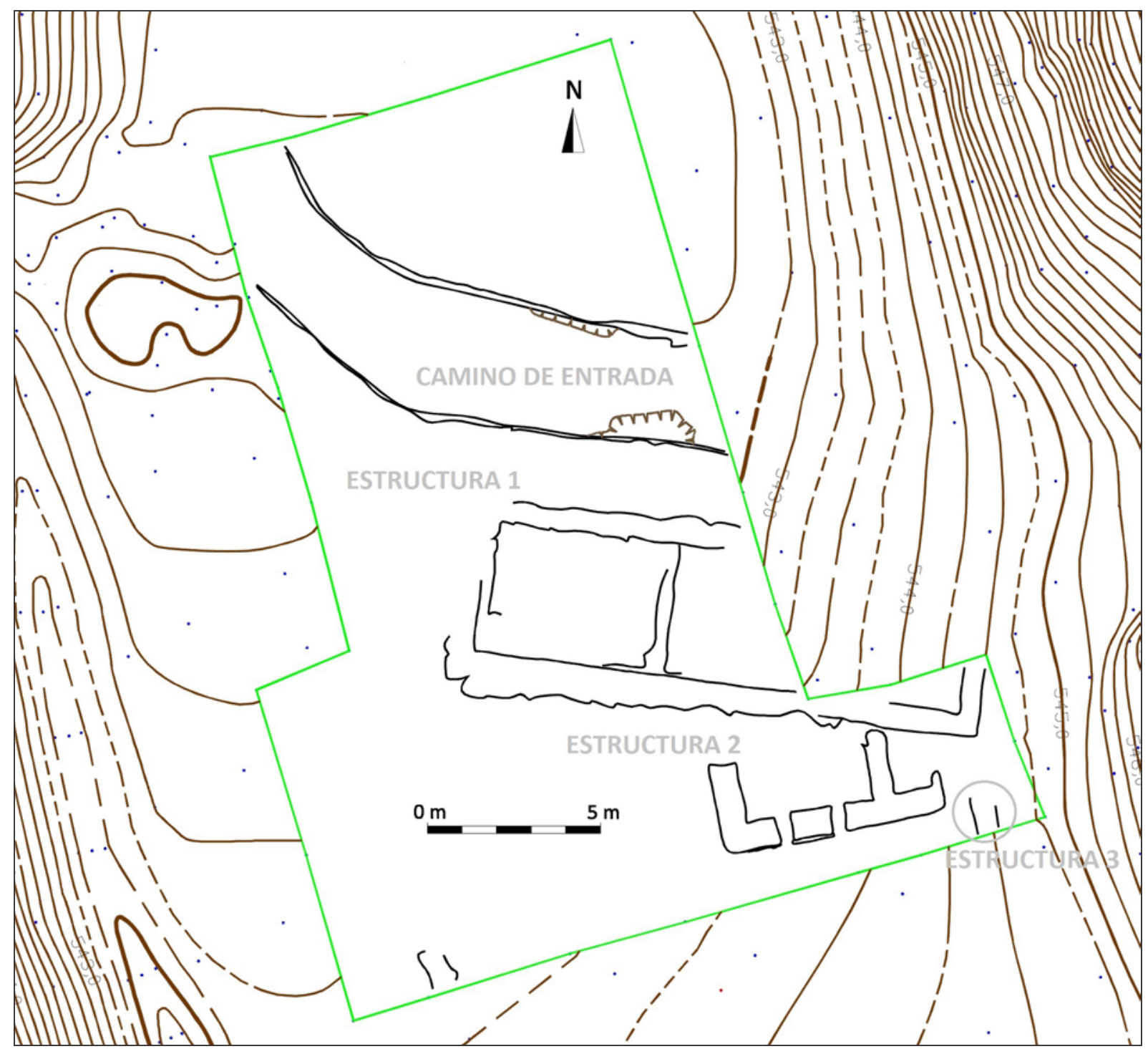

Figura 12. Planimetría de detalle del sector del antecastro oeste.

se sugirió en su momento (Arias Vilas y Fábregas Valcarce 2003).

La datación CSIC-896, la única realizada sobre material óseo, proviene de este mismo sector, pero más concretamente en el "recheo interior de terra da muralla principal” (Arias Vilas y Fábregas Valcarce 2003: 197). El contexto, se entiende, estaría relacionado con rellenos posteriores a la construcción de la muralla, lo que implicaría una datación post quem de esta entre el siglo IV y los últimos momentos del siglo I a. C. El interés principal de esta datación sería la de confirmar el origen prehistórico de la muralla, asociada a la primera ocupación del castro, pero sin descartar, per se, posteriores remodelaciones y acondicionamientos, que sí se han mostrado durante las recientes excavaciones en la muralla (López González et al. 2017).

Tanto CSIC-1321 como CSIC-1220 provienen de las excavaciones del antecastro oeste realizadas en la campaña de 1996. En este sector se localizaron tres estructuras superpuestas una a la otra. La secuencia descrita para este sector se dispondría, en síntesis, de la siguiente manera (fig. 12): la llamada estructura 2 estaría cortada por la estructura $1 \mathrm{y}$ ambas amortizadas por un estrato sobre el que se construye la estructura 3, la más reciente. La primera de las dataciones realizadas en el sector provendría del contexto VD.2.96.9B, 
asociado, según el informe de 1996 a "un anaco de viga... que se metía por baixo de muro de peche e polo tanto é de un momento anterior a éste muro" es decir, la "estructura 1". Siguiendo esta indicación, la datación mostraría entonces una fecha post quem de construcción de este edificio entre mediados del siglo IV y el I a. C. Hay que tener en cuenta que la construcción de esta estructura cortaba otra previamente existente (estructura 2), por lo que se podría sugerir que la datación señalaría también el momento ante quem de amortización de este edificio. En cualquier caso, este proceso ocurriría antes del cambio de era, lo que sería congruente con el análisis de materiales previamente expuesto.

Por su parte, la datación CSIC-1220 es la única que podemos asociar, por el momento, a los momentos finales de ocupación del sitio en época post-romana. $\mathrm{Al}$ igual que CSIC-1321, la muestra se tomó del antecastro oeste, y se asocia a "un anaco de madeira sita no camiño de acceso, o pé do muro que delimitada a rúa... polo que pertence a un momento de abandono do camiño". La datación mostraría, por lo tanto, un momento post quem de abandono de este camino entre el s. V y los momentos iniciales del s. VII d. C., cronología que encajaría bien con la propuesta de un abandono del sitio en los primeros compases del siglo VI d.C., si bien no es especialmente elocuente por sí misma. Por desgracia, esta datación proviene de un contexto estratigráfico especialmente abierto y sin material arqueológico que permita aquilatar esta horquilla.

\subsection{Análisis de un contexto estratigráfico}

En su trabajo sobre la sigillata de Viladonga, J.M. Caamaño y J.R. López enunciaban uno de los problemas esenciales a la hora de abordar el sitio: "este yacimiento dio materiales muy interesantes, pero su estudio se ve dificultado, lo mismo que sucede con la cerámica, porque los materiales no aparecen clasificados por estratos" (Caamaño Gesto y López Rodríguez 1984: 158). En efecto, la metodología utilizada por M. Chamoso en las primeras excavaciones en Viladonga, hija de su tiempo y basada en la metodología desarrollada por M. Wheeler (Ayán Vila 2012: 131-142), a partir de la definición de cuadrículas, su excavación hasta un punto aleatorio -agotando o no la estratigrafía de cada una de ellas- y la clasificación y unificación de todo el material aparecido en la cuadrícula, impiden los análisis secuenciales y estratigráficos. Sin embargo, las campañas más recientes, realizadas con una metodología estratigráfica, permiten ser más precisos sobre la secuencia.
Desarrollaremos un ejemplo concreto de secuencia estratigráfica, escogido por ser el mejor ejemplo disponible en el yacimiento hasta el momento, si bien la hipótesis que se maneja es que podría extenderse a prácticamente la totalidad del asentamiento. Se trata, en concreto, de un sector en la entrada este (fig. 13). Durante la campañas de 2006 se excavó sobre un sector de la muralla, y cuyo objetivo era delimitar la entrada este del castro. Durante la excavación se documentaron algunas estructuras adosadas a la muralla que fueron posteriormente excavadas en extensión en campañas siguientes. Este nuevo espacio no había sido anteriormente intervenido, lo que ofrecía una de las estratigrafías menos alteradas en el yacimiento. En síntesis, durante estas campañas se exhumaron hasta tres estructuras de planta rectangular con esquinas redondeadas, tipología muy común en la arquitectura doméstica del noroeste peninsular del período (Ayán Vila 2012), así como algunas construcciones "anteriores”, que, según los excavadores, indicarían la existencia "dunha remodelación urbanística neste espacio do novo Barrio da croa". Es interesante destacar que las estructuras superiores se construyeron reutilizando materiales, como demuestra la presencia de fragmentos de molinos circulares en los paramentos, lo que reforzaría la idea de dos grandes fases diferenciadas (fig. 14).

La estratigrafía asociada a las tres estructuras principales es relativamente sencilla como demuestra la propuesta de matriz Harris correspondiente (fig. 15). Es importante destacar que en ningún punto de este contexto se agotó la estratigrafía, si bien en algunos espacios específicos se excavó por debajo del nivel de cimentación, donde se localizaron algunas estructuras anteriores. Concretamente, cabe hacer mención de la denominada como "Estructura 4" y definida por los excavadores como una estructura "que sirve de base e cimentación a parte dos muros das vivendas 2 , enteiramente exhumada, e 3, parcialmente escavada na actual campaña" así como un posible muro bajo la estructura 1 que no fue delimitada por completo.

En la tabla 4 se puede ver la distribución cerámica por cada uno de los estratos de esta secuencia, incluyendo también la presencia de otros materiales en el relleno.

En esta secuencia se observan dos hechos significativos. En primer lugar, que las tres estructuras superiores serían contemporáneas -al menos en cierto momento de la secuencia- y pertenecientes al último momento de uso como espacio doméstico de este sector del castro. Y, por otro lado, la presencia de una fase anterior asociada a estructuras previas, cuya construcción 


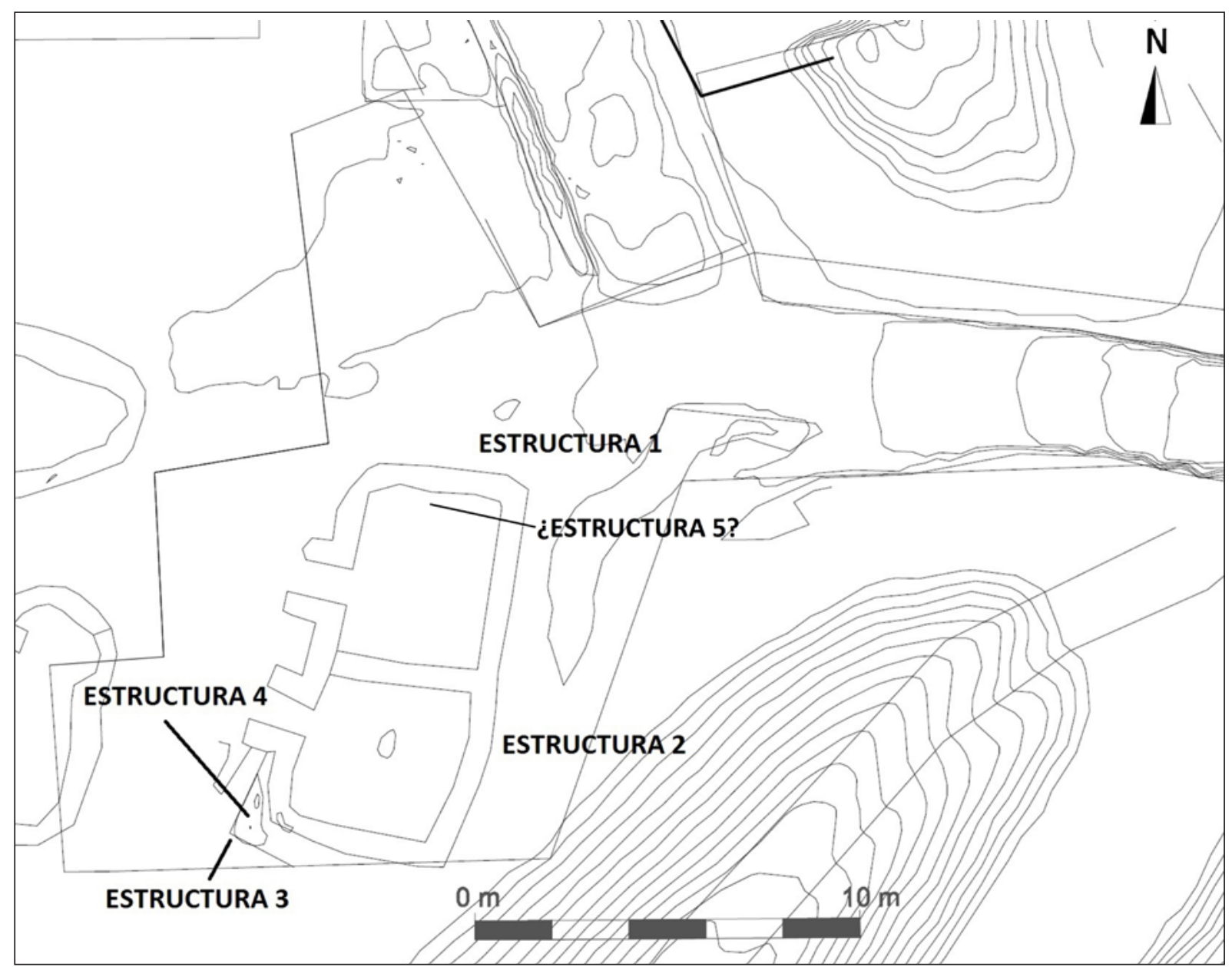

Figura 13. Planimetría de detalle del sector de la entrada este.

supuso una importante ruptura entre un momento y otro de la secuencia dado que se dieron cambios significativos en la organización urbanística así como la reutilización de materiales. La correlación de la cerámica con esta secuencia refuerza esta idea de ruptura neta entre, al menos, dos fases del yacimiento. Así, los estratos asociados con los derrumbes internos y las fases de ocupación de las tres estructuras de la segunda fase tienen materiales que remitirían fundamentalmente a momentos de la quinta o sexta centuria asociados al lógico material residual de época prehistórica. Por ejemplo, la UE 13Ñ2NIIC5, asociada al derrumbe interior de la Estructura $1 \mathrm{y}$, posiblemente, a los niveles de abandono de la misma, contenía un significativo conjunto de fragmento de CTOs características de los siglos V e inicios del VI d. C. Una UE muy similar sería la AB29NIIC12, descrita como "interior da vivienda 2" y que contenía un conjunto similar al ya comentado de cerámicas que marcarían un momento de abandono, al menos, en la quinta centuria y muy probablemente a partir de su segunda mitad.

Por el contrario, las escasas UEs excavadas por debajo de los niveles de cimentación de las estructuras únicamente contenían materiales asociados a CTOs prehistóricas o, en todo caso, en torno al cambio de era. Por ejemplo, la UE 13Ñ1NIVC18 "baixo o pavimento da Estrutura 1" y asociada a una "nivelación" para la estructura $1 \mathrm{y}$ su inmediatamente inferior, la UE 13Ñ1NIVC20, contenían un número significativo de cerámica prehistórica y de ciclos de cerámica común romana así como un denario de acuñación augústea datable en el siglo I d. C. De este nivel se comenta en el informe que "a natureza e características morfolóxicas e estratigráficas da capa térrea, abre a posibilidade de que sexa a testemuña, aínda que sexa en posición secundaria, dunha fase anterior do poboado 
¿CONTINUIDAD O DISCONTINUIDAD EN LOS CASTROS DEL NOROESTE? UNA REVISIÓN...

\begin{tabular}{|c|c|c|c|c|c|c|c|c|c|c|c|c|c|c|c|c|c|c|c|c|}
\hline 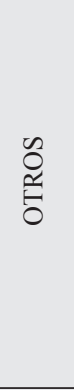 & & & & & 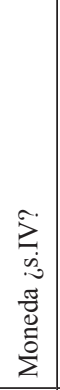 & & & 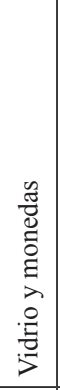 & 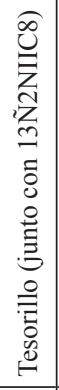 & 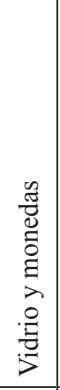 & & & & & 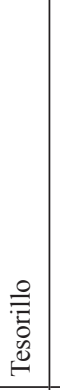 & & 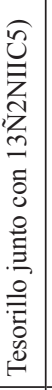 & 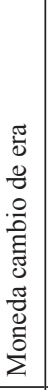 & & \\
\hline$\underset{\xi}{\vec{E}}$ & n & $\stackrel{\infty}{-1}$ & $N$ & $\vec{\sim}$ & $r$ & - & $m$ & $N$ & $\tilde{\infty}$ & 0 & $n$ & 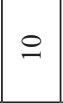 & -1 & $\sim$ & $N$ & - & $\sim$ & q & $\simeq$ & - \\
\hline 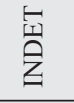 & $N$ & & & & & & & & $a$ & & & & & & & & & & & - \\
\hline 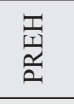 & & - & & $m$ & & & & & $=$ & & & $\sigma$ & - & & & & & $\approx$ & $\simeq$ & \\
\hline$\underset{\cong}{\cong}$ & & & & - & & - & & & $N$ & & & & & & & & $\sim$ & & & \\
\hline$\stackrel{\mathscr{\vartheta}}{\approx}$ & & $\sim$ & 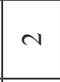 & $r$ & $N$ & & & & $\stackrel{p}{ }$ & 0 & $\sim$ & - & & - & & - & & $\sim$ & & \\
\hline 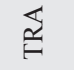 & & & & & & & & $\sim$ & & & & & & & & & & & & \\
\hline $\begin{array}{l}\dot{0} \\
\text { Oे } \\
\text { Z } \\
\end{array}$ & $m$ & \pm & & - & & & $\sim$ & & $=$ & & - & $m$ & & - & $N$ & & & & & \\
\hline ర్ర & & - & & $r$ & in & & - & & $\simeq$ & & $\sim$ & & & & & & & $\approx$ & & \\
\hline$\tilde{z}$ & & & & & & & & & $\mathrm{~N}$ & & & & & & & & & & & \\
\hline 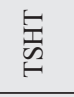 & & & & & & & & & & & & $\sim$ & & & & & & & & \\
\hline 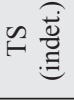 & & & & $\sim$ & & & & & & & & & & & & & & & & \\
\hline 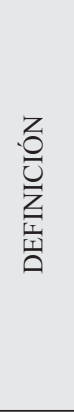 & 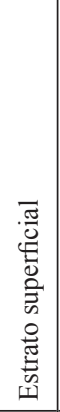 & 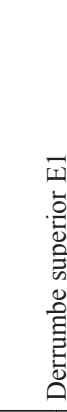 & 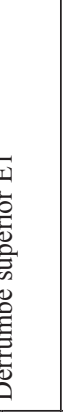 & 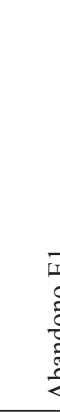 & 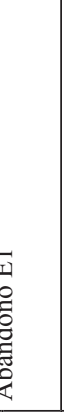 & & & & T & & & & & & 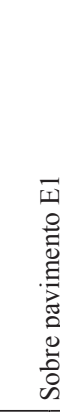 & & & 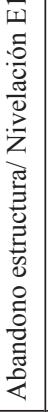 & & 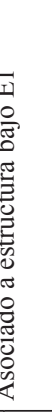 \\
\hline 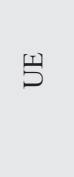 & $\begin{array}{l}8 \\
\dot{0} \\
z \\
z \\
z \\
-2\end{array}$ & 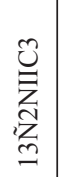 & 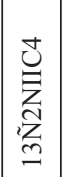 & 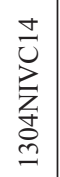 & 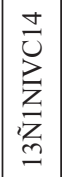 & 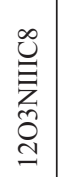 & 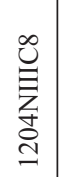 & 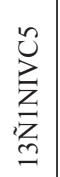 & 忌 & $\begin{array}{l}\stackrel{n}{n} \\
\overbrace{z}^{z} \\
\text { 总 }\end{array}$ & 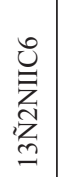 & 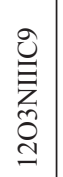 & 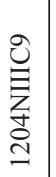 & 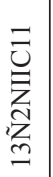 & 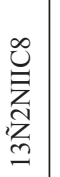 & 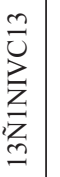 & 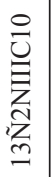 & $\begin{array}{l}\infty \\
\vec{U} \\
\underset{z}{z} \\
\underset{\sim}{z}\end{array}$ & 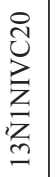 & $\begin{array}{l}0 \\
0 \\
0 \\
Z \\
0 \\
0 \\
0 \\
0\end{array}$ \\
\hline
\end{tabular}




\begin{tabular}{|c|c|c|c|c|c|c|c|c|c|c|c|c|c|}
\hline $\begin{array}{l}\tilde{n} \\
0 \\
\tilde{\Xi} \\
0\end{array}$ & & & & & 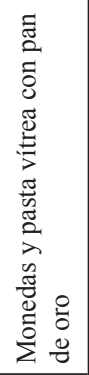 & & 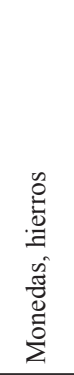 & 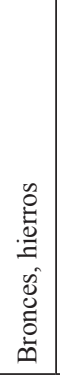 & & 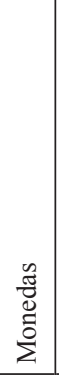 & & & \\
\hline 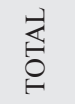 & $\sim$ & ন & $n$ & $\stackrel{\Xi}{\Xi}$ & $\sigma$ & in & f & $\circ$ & in & $n$ & $m$ & $\sim$ & $\begin{array}{l}\infty \\
\infty \\
0\end{array}$ \\
\hline 画 & & $n$ & - & $=$ & $\pi$ & - & $\nabla$ & & & & & & in \\
\hline 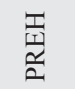 & & & & $\stackrel{ذ}{\sim}$ & $\tilde{\infty}$ & $\vec{n}$ & $\stackrel{i}{ }$ & $\circ$ & in & $n$ & $m$ & - & ț \\
\hline$\underset{\cong}{\mathscr{F}}$ & & & & & N & & - & & & & & & $a$ \\
\hline$\stackrel{\widetilde{\approx}}{\mathscr{F}}$ & - & in & & 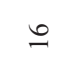 & in & $N$ & in & & & & & - & $\Xi$ \\
\hline$\overleftrightarrow{\cong}$ & & & & & & & & & & & & & $\sim$ \\
\hline $\begin{array}{l}\stackrel{\otimes}{0} \\
0 \\
\text { Z्य }\end{array}$ & & - & & & $\infty$ & - & 0 & & & & & & 8 \\
\hline త্ & - & $a$ & + & $\bar{n}$ & $\vec{n}$ & $m$ & in & & & & & & $\underline{n}$ \\
\hline$\tilde{z}$ & & & & & - & & & & & & & & $m$ \\
\hline $\overrightarrow{V_{n}}$ & & & & $\simeq$ & & & & & & & & & \pm \\
\hline$\omega \stackrel{\widehat{\vec{d}}}{\underline{g}}$ & & & & & & - & & & & & & & $m$ \\
\hline 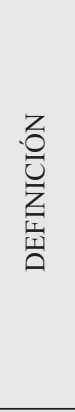 & $\dot{\delta}$ & $\begin{array}{l}y \\
0 \\
0 \\
0 \\
0 \\
0 \\
0\end{array}$ & 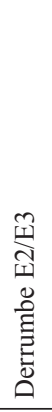 & 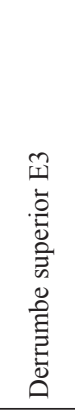 & 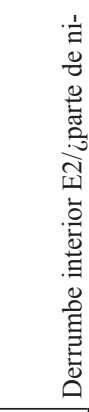 & & 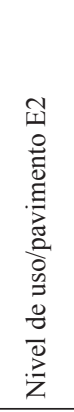 & 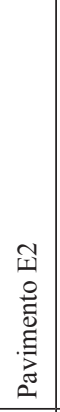 & 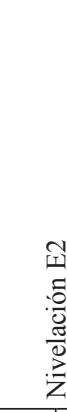 & & 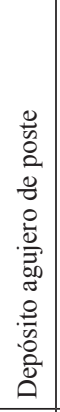 & 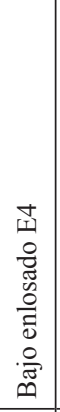 & $\begin{array}{l}\vec{E} \\
\stackrel{5}{0}\end{array}$ \\
\hline 预 & 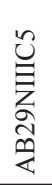 & 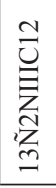 & 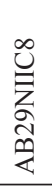 & 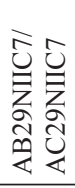 & 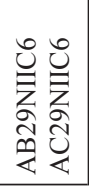 & 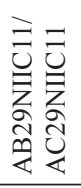 & 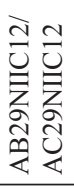 & 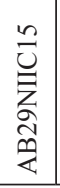 & 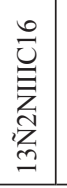 & 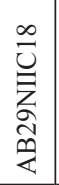 & 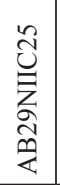 & 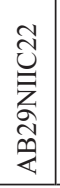 & \\
\hline
\end{tabular}



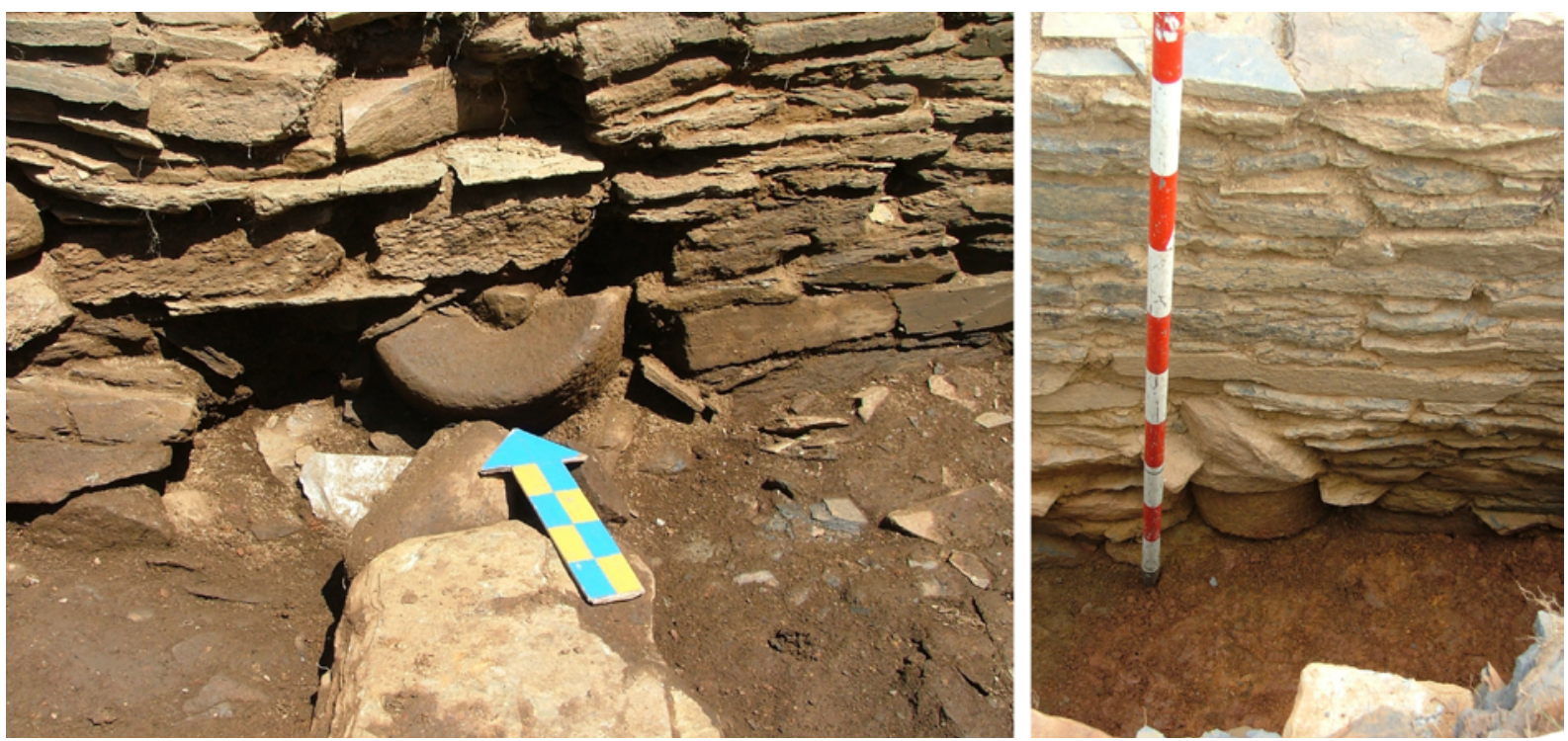

Figura 14. Molinos reutilizados en los cimientos de dos estructuras. Fotografía del informe de excavaciones de 2007 (AXA Arqueologia).

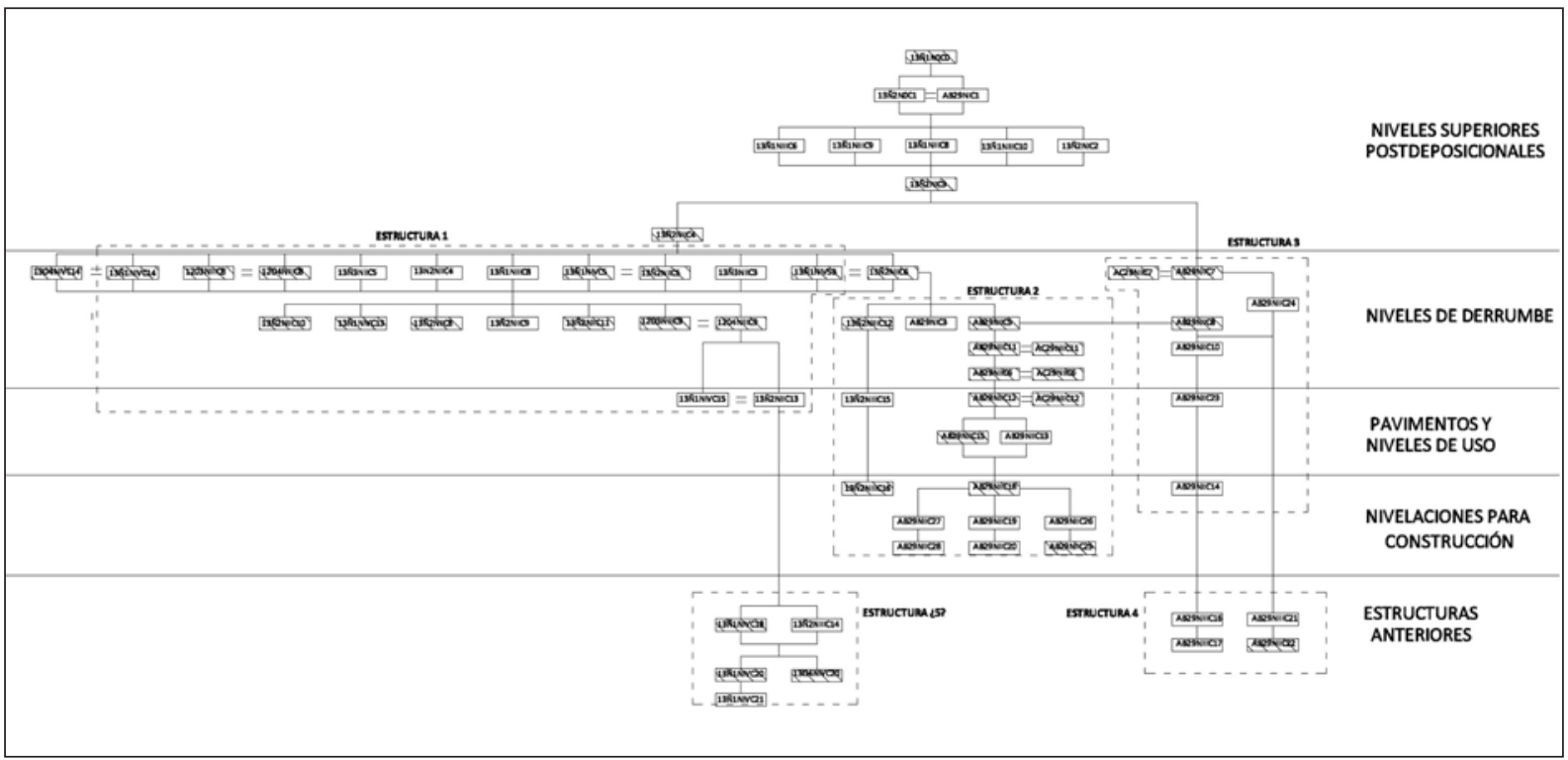

Figura 15. Secuencia estratigráfica del sector analizado. Los estratos rayados son aquellos que proporcionaron material cerámico. Elaboración propia a partir de los informes.

castrexo, fase de menor grao de romanización que a correspondente ó momento final de uso da estrutura desde nivel, dada a menor porcentaxe de cerámica desta filiación cultural". Es más, el único estrato asociado a la estructura 4, un depósito anterior a un enlosado (UE AB29N2C22) proporcionó dos fragmentos de material claramente prehistórico, reforzando con ello la hipótesis de dos grandes momentos de ocupación y una fase de ruptura entre los siglos II y IV d. C. (fig. 16).

Habría que comentar algunos estratos que se salen de esta norma, correspondientes a las UEs AB29NIIC6/ AC29NIIC6 y AB29NIIC1/AC29NIIC11. Ambas formarían parte de la misma parte de la secuencia de la Estructura 2, inmediatamente por encima y en contacto con el pavimento reconocido del suelo. Llama la 


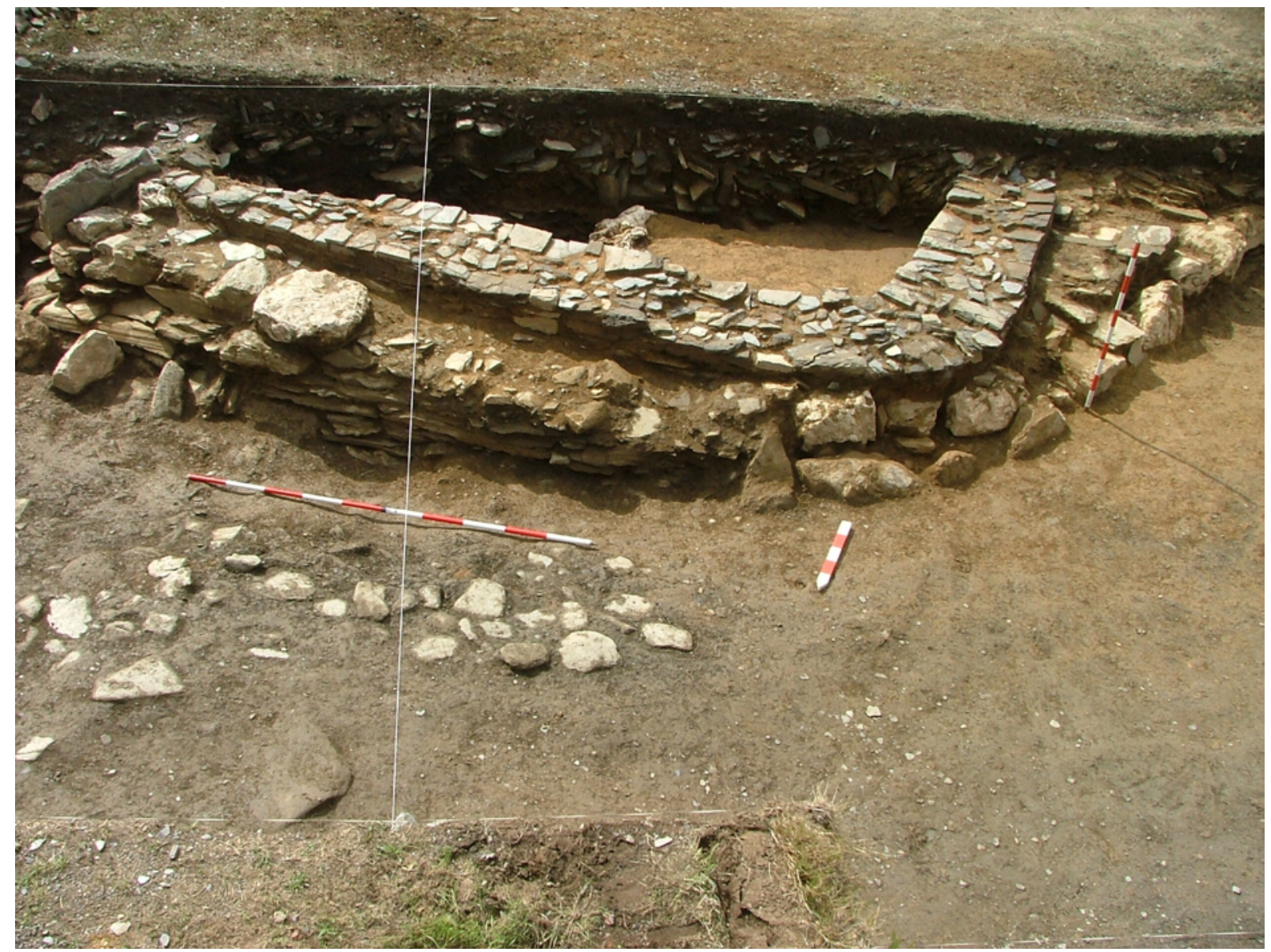

Figura 16. Estructura 1 de entrada este. Fotografía del informe de excavaciones de 2006 (AXA Arqueologia).

atención la numerosa presencia de cerámica prehistórica en estas UEs (42 y $87 \%$ respectivamente) y que supone de hecho el $70 \%$ de todo el material prehistórico recuperado en la secuencia. En ambos estratos esta cerámica está asociada a material mucho más tardío, por lo que se entiende que sería residual, a pesar de las cantidades mencionadas. La hipótesis que se propondría para explicar esta excepcional presencia de material prehistórico en estratos asociados a derrumbes interiores sería que durante su excavación se traspasaron los estratos de nivelación para la construcción de la estructura, donde originalmente se contenía este material. En cualquier caso, el conjunto cerámico de estas dos UEs presenta materiales claramente adscribibles a la quinta centuria, incluido uno de los escasos fragmentos de CIS presentes en todo el conjunto analizado y que se dataría sin duda en esta centuria (Juan Tovar 2012a). Es más, el estrato inmediatamente inferior asociado con el posible nivel de uso de la estructura (AB29NIIC12/ AC29NIIC12) también contiene material claramente tardío, lo que es plenamente coherente con la hipótesis de secuencia propuesta, al datar el momento de derrumbe y abandono de esta segunda estructura en momentos a partir de la segunda mitad del siglo $\mathrm{V}$ d. C.

Como se observa en la tabla, hay una importante presencia de moneda en esta estratigrafía, que permite completar la crítica estratigráfica, como se ha realizado en trabajos similares (King 2013) (fig. 17). Así, en uno de los estratos asociados al derrumbe de la Estructura 1 (13Ñ2N2C5) y otro, inmediatamente inferior, situado encima del pavimento (13ÑN2C10) se localizó un tesorillo compuesto por 336 monedas. De ellas, el 67\% (225 monedas) no pudieron ser determinadas. El resto, 111 monedas, fueron asociadas a las siguientes emisiones (tabla 5).

Salvo el único ejemplar de Claudio II, el resto de monedas se encuadran todas en la cuarta centuria. La moneda más moderna de Teodosio I (localizada en el estrato 13ÑN2NIC5) arrojaría una interesante fecha post 
Tabla 5. Emisiones localizadas en la Estructura 1.

\begin{tabular}{|l|c|c|}
\hline \multicolumn{1}{|c|}{ EMISIÓN } & FECHA & No MONEDAS \\
\hline Claudio II Gótico & $268-270$ & 62 \\
\hline Familia constantiniana & Inicios s. IV d.C. & 1 \\
\hline Constantino I & $306-337$ & 1 \\
\hline Licinio II & $308-324$ & 1 \\
\hline Helena & $326-360$ & 30 \\
\hline Serie Constantinópolis & $330-335$ & 2 \\
\hline Constancio II & $337-361$ & 6 \\
\hline Conmemoración de la muerte de Constantino I & 337 & 1 \\
\hline Constante & $337-350$ & 1 \\
\hline Constancio Galo & $351-354$ & 1 \\
\hline Juliano II Apóstata & $361-363$ & 1 \\
\hline Valente & $364-378$ & 1 \\
\hline Valentiniano I & $364-365$ & 11 \\
\hline Graciano & $375-383$ & $379-392$ \\
\hline Teodosio I & TOTAL & 1 \\
\hline
\end{tabular}

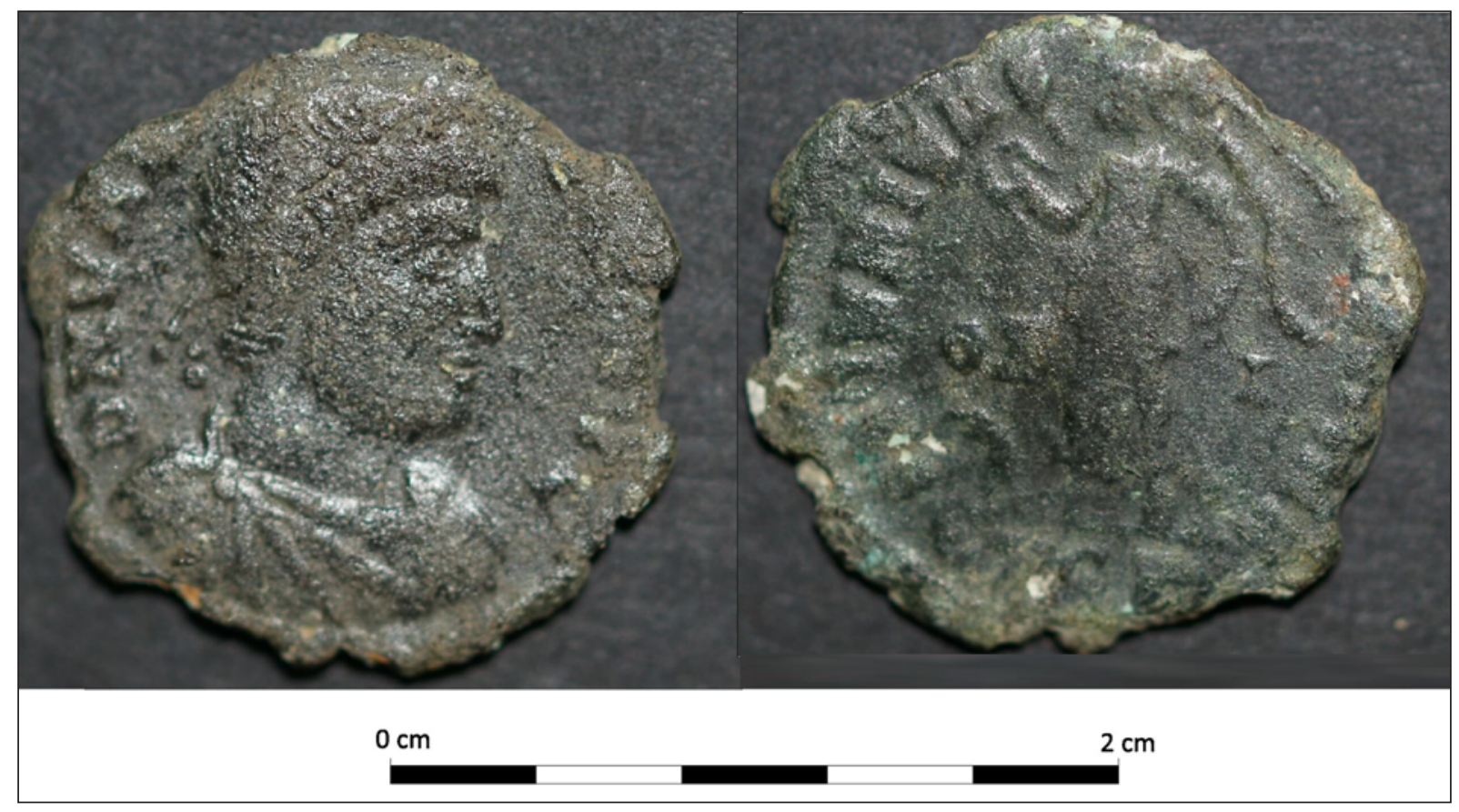

Figura 17. Algunas monedas del estrato asociado al derrumbe de la Estructura 1. Fotografías de Terra Arqueos. 
quem de finales de la cuarta centuria. Como se acaba de proponer, a partir del análisis cerámico este derrumbe se dataría ya dentro de la quinta centuria, posiblemente en su segunda mitad. Estos dos datos son plenamente coherentes en cuanto que lo que se estaría datando a partir de la cerámica serían fundamentalmente los momentos de abandono y desmantelamiento de la estructura si bien estaría muy posiblemente ocupada con anterioridad. Concretamente, en el estrato inferior 13ÑN2NIIC10 se localizaron dos fragmentos de la cadena TRC, adscribible a la quinta centuria o, incluso, a inicios de la sexta centuria. El lapso entre una datación y otra vendría dada, razonablemente, por la presencia de numerario acuñado durante el siglo IV pero atesorado en estos momentos (Marot 2000-2001). De hecho, el uso de numerario tardoimperial en contextos muy posteriores es algo bien documentado en otros contextos europeos. Por ejemplo, en un detallado estudio de la Crypta Balbi (Roma) se demostró el uso de moneda del s. III d. C. durante el s. VII d. C. (Saguì y Rovelli 1998).

Cabe destacar que en este mismo estrato 13Ñ2NIIC5 se documentaron dos fragmentos de vidrio (07/374 o 07/349-1) de formas similares a los tipos 109 de Isings datados en torno al siglo IV y VI d.C. (Isings 1957), lo que reforzaría la datación propuesta.

\section{PROPUESTA DE SECUENCIACIÓN DEL CASTRO DE VILADONGA}

Expuestos todos los datos y análisis, desarrollaremos ahora una propuesta de secuenciación del castro de Viladonga por fases:

- Fase 1. Primera ocupación del castro (ss. IV/III a. C.-inicios s.II d. C.). Esta fase cabría dividirla en dos subfases

- Fase 1a. Ocupación de la Prehistoria Reciente (ss. IV/III a. C.-I a. C.). Si bien no se puede por el momento ser más preciso con el momento exacto de la primera ocupación del castro, tanto el material cerámico como la datación del relleno de la muralla señalarían un momento en torno al siglo IV-III a. C. Esta fase marcaría la ocupación del castro dentro de lo que se ha venido denominando la cultura castrexa en un momento de rearticulación del poblamiento a escala regional con una intensificación en la ocupación de este tipo de contextos fortificados y asociado a intensas transformaciones sociales y culturales de las poblaciones indígenas (González Ruibal 2006-2007).
- Fase 1b. Conquista y asimilación romana (s. I a. C.-primera mitad del s. II d. C.). La conquista del noroeste por parte del ejército romano y la asimilación territorial y social de las poblaciones indígenas provocó un fuerte impacto que tuvo su repercusión en Viladonga (Rodriguez Resino 2006: 168). Aspectos muy significativos de la cultura material, como la cerámica -introducción de tecnologías de torno o de producciones como la sigillata - o la arquitectura doméstica con nuevas tipologías constructivas (Ayán Vila 2012)-, muestran cambios importantes en este momento. De hecho, como hipótesis, es posible que sea en esta fase cuando se produzca la expansión del castro fuera del contexto de las murallas, como se observaría en el antecastro oeste, proceso que ha sido documentado en otros yacimientos similares (Arias Vilas 1993; Rodríguez Fernández 1994; Sánchez Pardo 2010a).

- Fase 2. Primer abandono del castro (primera mitad del s. II d. C.-finales del s. IV d. C.). Como se ha venido defendiendo a lo largo de este trabajo, hay indicios muy significativos de que durante este período se produce un abandono del castro, al menos en las zonas excavadas de la croa y del antecastro. Esto no descarta la posibilidad de que los entornos del castro pudieran estar habitados -hay que recordar la presencia de la cercana villa de Doncide, cuya ocupación precisamente en estos momentos ha sido reiteradamente afirmada (Arias Vilas 1993)-, del mismo modo que cabe la posibilidad de que se pudieran dar otro tipo de usos a la croa, como por ejemplo de espacio agrario, tal y como ha sido propuesto recientemente para Elviña (Bello Diéguez 2018). Lo que se afirmaría a partir del análisis realizado es el abandono en la ocupación doméstica del sitio. Desafortunadamente, son pocos los contextos que podrían evidenciar arqueológicamente esta fase, si bien habría que hacer mención a las estructuras inferiores de la entrada este, cuyos estratos de abandono se vincularían con esta fase.

- Fase 3. Reocupación del castro (finales del s. IV d. C.-inicios del s. VI d. C.). En un momento que podemos datar en los últimos compases del s. IV y, probablemente, ya dentro de la quinta centuria se produce una segunda ocupación del castro, que perdurará hasta inicios del s.VI d. C., no más allá de la mitad de esta centuria. Es en este momento cuando se produciría una importante reestructuración que supondría, por ejemplo, la nivelación de gran parte del sitio para la instalación de nuevas estructuras, 
como se vería en la secuencia descrita de la entrada este. Es en estos depósitos de nivelación donde, precisamente, se localiza la mayor parte del material prehistórico procedente de la fase 1 , como se atestigua en la estratigrafía analizada.

- Fase 4. Segundo abandono del castro y usos posteriores (inicios del s.VI d. C.-¿?). Este segundo abandono se produciría a inicios de la sexta centuria, a tenor de los análisis realizados. La única datación radiocarbónica asociada a este momento, y con una calibración entre el primer tercio del siglo V d.C. e inicios del siglo VII d.C. si bien encaja con la propuesta, no permite precisarla más. Por el contrario, y teniendo en cuenta el material arqueológico, no se ha detectado ningún contexto estratigráfico, al menos conocido hasta el momento, que pueda ser datado más allá de este primer tercio del siglo VI d.C. Del mismo modo, no se han reconocido arqueológicamente otras ocupaciones posteriores en el castro, si bien todavía no se pueden descartar completamente. Lo más probable es que el lugar se convirtiera en algún momento indeterminado en espacio de cultivo, funcionalidad que se mantendría al menos hasta inicios del siglo XX, momento en el que Pilar Palmeiro y José Abelleira, pareja campesina de la zona, descubrirían los torques que darían a conocer la antigüedad de Viladonga, precisamente mientras labraban el terreno (Arias Vilas et al. 2013: 23). Igualmente, no hay que olvidar que este tipo de castros fueron utilizados, especialmente en el noroeste, como elementos simbólicos para la delimitación del paisaje y de las propiedades por parte de las comunidades locales a lo largo de todo este período (Lixó Gómez 2016).

Esta secuenciación es una propuesta derivada de los datos y análisis expuestos, y, por lo tanto, sujeta a crítica y modificaciones. Sin embargo, creemos que hay evidencias suficientes en el conjunto de datos aportados para sostener esta secuenciación en el castro de Viladonga. Esta nueva propuesta implica, además, algunas cuestiones interpretativas que serán comentadas en el siguiente apartado.

\section{DISCUSIÓN: VILADONGA Y LA OCUPACIÓN TARDÍA DE LOS CASTROS EN LA GALLAECIA}

Como indicábamos al inicio, el castro de Viladonga fue uno de los sitios fundamentales sobre los que se vertebró la narrativa en torno al poblamiento tardoimperial y de época sueva en la antigua Gallaecia. Varias son las consecuencias interpretativas y de discusión derivadas de la secuenciación que se ha propuesto. En este último apartado delinearemos únicamente algunas de las más significativas a modo de reflexión y de agenda de trabajo, desde las más particulares a las más generales.

- Revisión de otros elementos arqueológicos de Viladonga. El propio contexto de Viladonga debería ser repensado a la luz de estas consideraciones. Por ejemplo, a partir de la propuesta de dos grandes fases con un abandono intermedio de casi tres centurias, cabría revisar algunos aspectos particulares, por ejemplo, relativos a la arquitectura doméstica. Un aspecto muy particular de Viladonga es la supuesta presencia de arquitectura doméstica de formato circular en momentos "tardíos", algo que no ocurre en ningún otro caso en todo el norte peninsular durante este período (Tejerizo García 2013) y que sería conveniente revisar. A modo de hipótesis de trabajo, lo que se plantearía es que las arquitecturas de formato circular pertenecerían fundamentalmente a la fase 1a aquí propuesta y que la actual disposición del yacimiento estuviera reflejando las arquitecturas domésticas y planimetrías de dos momentos diferenciados. Esta secuencia entre edificios circulares -más antiguos- y edificios cuadrangulares ha sido observado estratigráficamente en otros yacimientos similares del noroeste peninsular, como en Formigueiros (Dorribo Cao 1995; Fernández Pereiro et al. 2017). En cualquier caso, cabe señalar que en toda la secuencia parece respetarse la distribución urbana del yacimiento, en cuanto que en ninguno de los caminos y calles principales del sitio se han construido estructuras en ninguna de las fases de ocupación -al menos, aparentemente-, lo que implicaría una continuidad de ciertos parámetros urbanísticos en toda la secuencia, como ya se ha propuesto en otros trabajos (Ayán Vila 2003).

- Revisión de contextos similares. La conclusión más obvia es que, de ser cierta esta propuesta de secuencia del castro de Viladonga, sería extremadamente interesante la revisión particular de otros contextos similares en el contexto del noroeste peninsular, caso de yacimientos emblemáticos como San Cibrán de Las, Fazouro, A Lanzada, etc..., interpretados y secuenciados de forma similar -y en ocasiones, a consecuencia de- Viladonga. En ningún caso se sugiere que las secuencias de otros yacimientos deban ser similares a la aquí propuesta, sino más 
bien que, a tenor de los nuevos avances en la datación de los contextos tardoimperiales y altomedievales se puedan actualizar y discutir las secuencias de sitios excavados en un contexto historiográfico distinto. De nuevo, se plantea que únicamente mediante un conocimiento exhaustivo de la secuencia de cada yacimiento particular se pueda realizar un análisis arqueológico sin apriorismos que sostengan un relato sólidamente argumentado sobre las transformaciones ocurridas en el noroeste peninsular tras el fin del Imperio Romano, como se ha venido sugiriendo (Rodriguez Resino 2006: 170-171; Sánchez Pardo 2010a, 2012; Vigil-Escalera y Tejerizo García 2014).

- El concepto "galaico-romano". Otro aspecto que entendemos debería ser repensado es el propio concepto de lo "galaico-romano" como un período cultural homogéneo, al menos como se ha venido entendiendo tradicionalmente. En un reciente trabajo, J.C. Sánchez sugería que "al estudiar un castro en el paisaje, en nuestra opinión, debemos desligarlo de cualquier asociación automática a una etapa cronocultural concreta, pues en todas ellas, de distintas maneras, juega un papel concreto. Lo que debemos es analizar cuáles son y cuándo se dan esas funciones" (Sánchez Pardo 2010a: 132). El impacto que la conquista romana tuvo en el sistema de poblamiento y en el paisaje del noroeste peninsular no solo fue muy significativo a nivel cultural y simbólico (González Ruibal 2006-2007), sino que también tuvo sus diferentes etapas y formas de articulación social y territorial a lo largo de los cuatro siglos que suponen la dominación romana en la península ibérica. Únicamente mediante la contextualización territorial y social de cada yacimiento se pueden observar los procesos particulares encerrados -a veces de forma muy hermética y utilizados acríticamente- en conceptos como el de "galaicoromanos". No se trataría de desechar el concepto, sino de repensarlo contextualmente

- La continuidad de los castros. Igualmente, cabría reconsiderar el tema de la continuidad - $\mathrm{O}$ no continuidad en este caso- de los castros a lo largo del período de dominación romana y en época sueva. En el primer caso lo que se plantea es que el abandono de Viladonga entre los siglos II y IV d. C. se explicaría como una consecuencia de la estrategia de dominación imperial romana, destinada a la desvertebración de las antiguas redes de poblamiento y su redefinición dentro de los parámetros de la lógica colonial del Imperio (Tejerizo García y Vigil-Escalera Guirado 2017). Esto supondría lo que en repetidas ocasiones se ha denominado como "bajada" de las poblaciones de los castros hacia los espacios en llano, dentro de una lógica económica destinada al cultivo de las grandes extensiones de terreno que, en período tardoimperial, se asociaban fundamentalmente - pero no solo- a las villas latifundistas (Arias Vilas 1987, 1996; Rodríguez Fernández 1994). En este caso, se plantea que los habitantes del sitio de Viladonga se insertarían dentro de esta lógica, y que villas como la de Doncide, a escasos kilómetros del yacimiento, funcionaran como polos articulador de la población, como ya ha sido propuesto (Arias Vilas 1993).

Esta forma de estructurar el poblamiento tendría un momento de ruptura durante el siglo $\mathrm{V} \mathrm{d}$. C. que supondría, como hemos sugerido, la re-ocupación de castros como Viladonga pero bajo una lógica diferente (Tejerizo García y Canosa Betés 2018). La larga duración de las tradicionales propuestas cronológicas de los castros obligaban a pensar el paisaje del tardoimperio como un espacio con tres polos que incluían las ciudades, las villas y los castros (Gutiérrez González 2014; Tranoy 1981: 422). Algunos autores, como A. Tranoy o F. Arias, interpretaban esta contemporaneidad de las villas y los castros en el medio rural bajo una mirada dicotómica entre los propietarios ricos, que vivirían en las villas, y la población local, que utilizaría los castros como forma de defensa ante las inestabilidades de los siglos III-V d. C. Estas poblaciones locales se relacionarían, según estos autores, con "campesinos-soldados", milicias privadas dependientes, y defensores, de los propietarios de las villas (Arias Vila 1996: 184). Sin embargo, lo que se sugeriría aquí es un panorama distinto, en el que las villas y los castros en época tardoimperial y altomedieval fueran el final y el comienzo de dos formas distintas de conceptualizar los paisajes sociales, como se ha sugerido para otros entornos peninsulares $(\mathrm{Gu}-$ tiérrez González 2014).

- El significado histórico de los castros en época tardoimperial y sueva. En este sentido, cabría hacer también una reflexión sobre el significado de estas re-ocupaciones fortificadas en altura durante el tardoimperio y la época sueva, cuyos orígenes y vinculaciones sociales y políticas han sido vistas desde una diversidad de interpretaciones (una síntesis en Gutiérrez González 2014). En el noroeste, tradicionalmente se habían vinculado estas ocupaciones con la inestabilidad derivada de 
la llegada de los suevos, los conocidos castella tutiora referidos en la crónica de Hidacio (Arias Vilas 1996; Lovelle y López Quiroga 2000; Novo Guisán 1994; Tranoy 1981). Sin embargo, la secuencia aquí propuesta para el castro de Viladonga desbordaría estos marcos de referencia. Nuestra propuesta llevaría a una ocupación del yacimiento que comprendería, grosso modo, el período entre el 380/530 d.C., lo que implicaría una ocupación más allá del momento de llegada de los suevos y de la crónica de Hidacio, centrada en el período 379-469. No se niega, por tanto, que castros como Viladonga funcionaran efectivamente como los castella tutiora de la tradición hidaciana, esto es, como espacios de mantención de poder de las élites locales en un momento de cuestionamiento de sus tradicionales privilegios sociales y económicos amparados por el Estado romano. Sin embargo, este sería únicamente uno de los distintos momentos dentro de la propia biografía del sitio y de sus habitantes. Así, se plantearía la problemática de cómo entender e insertar estos castros en las dinámicas de construcción del Estado suevo y de la posterior conquista por parte del Estado visigodo del noroeste peninsular, y cuestionarse quiénes son los agentes detrás de esta reocupación del castro de Viladonga (Gutiérrez González 2014). En este sentido, y como hipótesis, habría que entender estos entornos como espacios de relación de diversas escalas de poder, como las avenues of collaboration entre distintos agentes sociales, siguiendo el planteamiento de S. Castellanos e I. Martín Viso (Castellanos y Martín Viso 2005). La re-ocupación de castros como Viladonga, datada, como se ha propuesto, entre finales del siglo IV y a lo largo del siglo V d.C. respondería a una lógica vinculada a la restructuración del sistema de poblamiento en una escala local y regional (Tejerizo García y Canosa Betés 2018). En el caso de Viladonga, nuestra hipótesis, ya sugerida en otros trabajos, es que su reocupación obedecería a una rearticulación de los espacios centrales de control territorial por parte de las élites locales y regionales en un momento de cuestionamiento de este mismo control (Martínez Jiménez y Tejerizo García 2015). Esta rearticulación de los espacios centrales también tendría su reflejo arqueológico en los antiguos centros de control, que también muestran fuertes signos de transformación. En el caso de la cercana ciudad de Lugo, las excavaciones arqueológicas han mostrado repetidamente estas transformaciones, por ejemplo, en el abandono definitivo de algunos edificios suntuarios y la aparición de nuevas zonas de producción cerámica intramuros (Alcorta Irastorza y Bartolomé Abraira 2012; Díaz y Díaz 1995).

En cualquier caso, estos son solo algunas reflexiones y apuntes derivados del análisis llevado a cabo en Viladonga, que deberán ser contrastados, desarrollados o refutados en el futuro. Como decíamos al inicio, son muchos los avances de la arqueología tardoimperial y altomedieval en el noroeste que están permitiendo no solo desarrollar formas novedosas de entender el período sino también la redefinición de algunos problemas como los aquí considerados a partir del castro de Viladonga.

\section{Agradecimientos}

Este trabajo ha sido realizado en el marco del Proyecto "Agencia campesina y complejidad sociopolítica en el noroeste de la Península Ibérica en época medieval" (Ministerio de Economía, Industria y Competitividad, HUM2016-76094-C4-2-R), el Grupo de Investigación en Arqueología Medieval, Patrimonialización y Paisajes Culturales / Erdi Aroko Arkeologia, Ondaregintza eta Kultur Paisaiak Ikerketa Taldea, código IT1193-19 y el Grupo de Estudios Rurales (Unidad Asociada UPV/ EHU-CSIC) dirigidos por Juan Antonio Quirós Castillo y gracias a una beca de investigación postdoctoral financiada por la Xunta de Galicia. Agradecemos a Juan Antonio Quirós Castillo, José Carlos Sánchez Pardo y a Felipe Arias Vilas los comentarios y sugerencias a versiones anteriores del texto. Agradecemos también a Elena Varela y a todo el equipo técnico del museo del castro las facilidades y ayuda para realizar la revisión.Igualmente, agradecemos los comentarios de los evaluadores externos. Cualquier error es responsabilidad nuestra.

\section{BIBLIOGRAFÍA}

Alcorta Irastorza, E. J. (2001): Lucus Augusti (vol. II): cerámica común de cocina y mesa hallada en las excavaciones de la ciudad. A Coruña, Fundación Pedro Barrié de la Maza.

Alcorta Irastorza, E. J. y Bartolomé Abraira, R. (2012). "Muestras de cerámica engobada romana de producción local de Lucus Augusti (Lugo)", en D. Bernal Casasola y A. Ribera i Lacomba (eds.), Cerámicas hispanorromanas II. Producciones regionales: 699-724. Cádiz, Universidad de Cádiz. 
Arias Vila, F. (1996). "Poblamiento rural: la fase tardía de la cultura castreña", en C. Fernández Ochoa (ed.), Los finisterres atlánticos en la Antigüedad: época prerromana y romana: 181-188. Gijón, Electa España.

Arias Vilas, F. (1987): “Castros lucenses de época romana". Memorias de Historia Antigua 8: 7-16.

Arias Vilas, F. (1993): “Apuntes sobre a ocupación do territorio na Galicia baixorromana: castros e vilas", en Galicia: da romanidade á xermanización. Problemas históricos e culturais. Actas do encontro cientifico en homenaxe a Fermín Bouza Brey (1901-1973): 201-208. Santiago de Compostela, Instituto de Estudios Galegos "P. Sarmiento" - Museo do Pobo Galego - Universidade de Santiago de Compostela.

Arias Vilas, F. (1996). "Poblamiento rural: la fase tardía de la cultura castreña", en C. Fernández Ochoa (ed.), Los finisterres atlánticos en la Antigüedad: época prerromana y romana: 181-188. Gijón, Electa España.

Arias Vilas, F. y Durán Fuentes, M. C. (1997): “Apliques e botóns de bronce para persoas e cabalerías no Castro de Viladonga". CROA. Boletín da Asociación de Amigos do Museo do Castro de Viladonga 7: 14-18.

Arias Vilas, F.; Durán Fuentes, M. C.; Bastos Bernárdez, D. y Varela Arias, E. (2013): Museo do Castro de Viladonga (Castro de Rei, Lugo). Santiago de Compostela, Xunta de Galicia.

Arias Vilas, F. y Fábregas Valcarce, R. (2003): “Datacións radiocarbónicas do Castro de Viladonga (Lugo)". Gallaecia 22: 193-210.

Ayán Vila, X. (2003): “Arquitectura como tecnología de construcción de la realidad social". Arqueología de la arquitectura 2: 17-24.

Ayán Vila, X. (2012): Casa, familia y comunidad en la Edad del Hierro del NW. Santiago de Compostela, Xurimaru Servizos de Comunicación.

Bello Diéguez, J. M. (2018): "Bajo Imperio y Tardorromanidad en el Castro de Elviña (A Coruña)". Boletín del Museo Arqueológico Nacional 37: 131-148.

Bustamante Álvarez, M. (2013-2014): "La Terra Sigillata Gálica e Hispánica. Evidencias de algo más que una relación comercial". Romula 12-13: 561-581.

Caamaño Gesto, J. M. y López Rodríguez, J. R. (1984): "Sigillatas del castro de Viladonga (Lugo). I". Gallaecia 7-8: 158-177.

Castellanos, S. y Martín Viso, I. (2005): “The local articulation of central power in the north of the iberian
Peninsula (500-1000)". Early Medieval Europe 13, 1: 1-42.

Da Cruz, M. (2007): "Vidros do Castro de Viladonga (Lugo). Um caso exemplar". CROA. Boletín da Asociación de Amigos do Museo do Castro de Viladonga 17: 14-24.

Díaz y Díaz, M. C. (1995): "Notas sobre el distrito de Lugo en la época sueva". Helmántica 46, 139-141: 227-242.

Dorrego Martínez, F. y Rubiero Da Pena, A. M. (1998): "Consideracións sobre os temas decorativos na cerámica castrexa de Viladonga". CROA. Boletín da Asociación de Amigos do Museo do Castro de Viladonga 8: 21-28.

Dorribo Cao, J. R. (1995). “O castro de Formigueiros: unha aproximación ó seu estudo arqueolóxico" Historia Nova II: 9-24. Santiago de Compostela, Asociación galega de historiadores.

Durán Fuentes, M. C. (2000): "Una revisión de las monedas altoimperiales del Castro de Viladonga". CROA. Boletín da Asociación de Amigos do Museo do Castro de Viladonga 10: 16-20.

Durán Fuentes, M. C. (2009): Moedas do Museo do Castro de Viladonga. Santiago de Compostela, Xunta de Galicia.

Durán Fuentes, M. C. y Fernández Vázquez, M. P. (1999): "Anillos del Castro de Viladonga". CROA. Boletín da Asociación de Amigos do Museo do Castro de Viladonga 9: 30-34.

Fernández Fernández, A. y Bartolomé Abraira, R. (2016). "Cerámicas tardoantiguas en el noroeste de la Península (Galicia y norte de Portugal): entre la importación y el artesanado local/regional", en J. A. Quirós Castillo y A. Vigil-Escalera (eds.), La cerámica de la Alta Edad Media en el cuadrante noroeste de la Península Ibérica (siglos V-X): sistemas de producción, mecanismos de distribución y patrones de consumo: 69-111. Bilbao, Universidad del País Vasco.

Fernández Fernández, A.; Carvalho, P. C.; André, C.; Costa, M. y Tereso, S. (2018): "Contextos cerámicos de época alto y bajo imperial provenientes de $\mathrm{La}$ Torre Velha-Castro de Avelas (Bragança, Portugal)", en Rei Cretariae Romanae Fautores. Acta 45: 71-81.

Fernández Pereiro, M. (2017). "Mais lá da cultura castreja: castros ex-novo durante a antiguidade tardía no noroeste da Gallaecia”, en A. Vázquez Martínez, R. Cordeiro Macenlle, M. Carrero Pazos, M. Díaz Rodríguez, A. A. Rodríguez Novoa y B. Vilas Estévez (eds.), (Re)escribindo a historia. Achegas dos novos investigadores en arqueoloxía e ciencias 
da antigüidade: 287-298. Santiago de Compostela, Andavira Editora.

Fernández Pereiro, M.; Tejerizo García, C.; Rodríguez González, C.; Lixó Gómez, C. y Carvajal Castro, Á. (2017): “Asentamentos fortificados no interior da Gallaecia en época tardoimperial e sueva (séc. IV-VI): un achegamento a partir de varios casos de estudo". Gallaecia 36: 129-162.

Fuentes Domínguez, Á. (1990): "Los vidrios de las necrópolis de la Meseta: ensayo preliminar de clasificación". Cuadernos de prehistoria y arqueología de la Universidad Autónoma de Madrid 17: 169-202.

González Ruibal, A. (2006-2007): “Galaicos. Poder y comunidad en el Noroeste de la Península Ibérica (1200 a.C-50 d.C)". Brigantium 18: 11-272.

Gutiérrez González, J. A. (2014): "Fortificaciones tardoantiguas y visigodas en el norte peninsular (ss. V-VIII)", en R. Catalán Ramos, P. Fuentes Melgar y J. C. Sastre Blanco (eds.), Las fortificaciones en la tardoantigüedad. Élites y articulación del territorio (siglos V-VIII d.C.): 191-214. Madrid, La Ergástula.

Hevia González, S.; Montes López, R. y Benéitez González, C. (1999): “Cerámica común romana del Chao Samartín (Grandas de Salime-Asturias: vajilla de cocina y almacenamiento)". Boletín del Seminario de Estudios de Arte y Arqueología 65: 153-196.

Isings, C. (1957): Roman glass from dated finds. Groningen, J.B. Wolters.

Juan Tovar, L. C. (2012a): “Las cerámicas imitación de sigillata (CIS) en la Meseta Norte durante el siglo V. Nuevos testimonios y precisiones cronológicas", en C. Fernández Ibáñez y R. Bohigas Roldán (eds.), In durii regione romanitas. Homenaje a Javier Cortes: 365-372. Santander - Palencia, Diputación Provincial de Palencia - Instituto de Prehistoria y Arqueología Sautuola.

Juan Tovar, L. C. (2012b): "Las cerámicas imitación de sigillata en el occidente de la Península Ibérica durante el siglo V d.C.", en D. Bernal Casasola y A. Ribera i Lacomba (eds.), Cerámicas hispanorromanas II. Producciones regionales: 97-129. Cádiz, Universidad de Cádiz.

King, A. (2013): Coins and Samian Ware. A study of the dating of coin-loss and the deposition of Samian Ware (Terra Sigillata), with a discussion of the decline of Samian Ware manufacture in the NW provinces of the Roman Empire, late 2nd to mid 3rd centuries $A D$. Oxford, BAR International Series 2573. Oxford, Archaeopress.
Lage Pillado, M. (2004): Fíbulas galaico-romanas do Castro de Viladonga. Santiago de Compostela, Xunta de Galiza.

Lixó Gómez, C. (2016): "Los castillos en la Galicia medieval: balance historiográfico y perspectivas de futuro", en Estudiar la Edad Media en el siglo XXI: herencia, historiografía, coyuntura académica y renovación. Actas del IV Congreso Internacional de Jóvenes Medievalistas Ciudad de Cáceres. Roda da Fortuna, Revista Eletrônica sobre Antiguidade e Medievo 1-1: 259-292. Cáceres (2015), disponible en https://www.revistarodadafortuna.com/2016-1-1.

López González, L. F.; López Marcos, M. A.; López González, P. y Álvarez González, Y. (2017): "Campaña de intervención no Castro de Viladonga (2016)". CROA. Boletín da Asociación de Amigos do Museo do Castro de Viladonga 27: 16-31.

López Quiroga, J. (2004): El final de la antigüedad en la Gallaecia: la transformación de las estructuras de poblamiento entre Miño y Duero (siglos V al X). La Coruña, Fundación Pedro Barrié de la Maza.

López Quiroga, J. y Lovelle, M. R. (1999): “Castros y castella tutiora de época sueva en Galicia y norte de Portugal: ensayo de inventario y primeras propuestas interpretativas". Hispania Antiqua XXIII: 355-374.

Lovelle, M. R. y López Quiroga, J. (2000): “El poblamiento rural en torno a Lugo en la transición de la antigüedad al feudalismo (ss. V-X)". Cuadernos de Estudios Gallegos 47, 113: 53-76.

Llana Rodríguez, J. C. y Varela Arias, E. (2001): “Las primeras excavaciones en el castro de Viladonga, treinta años después". CROA. Boletín da Asociación de Amigos do Museo do Castro de Viladonga 11: 11-24.

Marín Suárez, C. (2012): “La cerámica de la Edad del Hierro en el sector centro-occidental cantábrico". Munibe 63: 165-198.

Marot, T. (2000-2001): "La península Ibérica en los siglos V-VI: consideraciones sobre provisión, circulación y usos monetarios". Pyrenae 31-32: 133-160.

Martín Viso, I.; Fuentes Melgar, P.; Sastre Blanco, J. C. y Catalán Ramos, R. (2018): Cerámicas altomedievales en Hispania y su entorno (s.V-VIII). Madrid, Glyphos.

Martínez Jiménez, J. y Tejerizo García, C. (2015): "Central places in the post-roman mediterranean: regional models for the Iberian Peninsula". Journal of Mediterranean Archaeology 28, 1: 81-103. 
Maya, J. L. y Cuesta Toribio, F. (2001): El Castro de La Campa Torres. Período prerromano. Gijón, VTP Editorial.

Mezquíriz, M. Á. (1961): Terra Sigillata Hispánica. Valencia, Domenech.

Molinero Pérez, A. (1971): Aportaciones de las excavaciones y hallazgos casuales (1941-1959) al Museo Arqueológico de Segovia. Excavaciones Arqueológicas en España 72. Madrid, Ministerio de Educación y Ciencia.

Novo Guisán, J. M. (1994): “¿Castros tardíos en el noroeste? Algunas menciones literarias visigodas y de la primera Reconquista". CROA. Boletín da Asociación de Amigos do Museo do Castro de Viladonga 4: 16-17.

Orton, C.; Tyers, P. y Vince, A. (1997): La cerámica en Arqueología. Barcelona, Crítica.

Paz Peralta, J. A. (1991): Cerámica de mesa romana de los siglos III al VI d.C en la provincia de Zaragoza. Zaragoza, Institución Fernando el Católico.

Paz Peralta, J. A. (2013). "La vajilla de cerámica hispánica tardía gris y naranja en Asturica Augusta (Astorga, León). Conjunto C", en Ex Officina Hispana. Cuadernos de la SECAH 1: 217-256. Madrid, La Ergástula.

Quirós Castillo, J. A. (2012). “Introducción”, en J. A. Quirós Castillo y J. M. Tejado Sebastián (eds.), Los castillos altomedievales del cuadrante noroccidental de la Península Ibérica: 17-27. Bilbao, Universidad del País Vasco.

Raynaud, C. (1993): «Céramique Estampée grise et orangée dite «derivée de sigillée paléochrétienne»»». Lattara 6: 410-418.

Rey Castiñeira, J. (2010). «A produción cerámica», en J. Rey Castiñeira, E. Abad Vidal, N. Calo Ramos, C. Candamo Bueno, M. Comesaña Cortegoso, M. Martín Seijo, G. Meijide Cameselle, N. Pena Monteagudo, I. Picón Platas, A. Rico Rey, C. Rodríguez Rellan y A. Teira Brion (eds.), Formigueiros. Análise da cultura material. Santiago de Compostela, Universidade de Santiago de Compostela. Inédito.

Rigoir, J. (1968): «Les sigillées paléochrétiennes grises et orangées». Gallia XXVI: 177-244.

Rodríguez Fernández, T. (1994): «El fin del mundo fortificado y la aparición de las «aldeas abiertas». La evidencia del centro-oriente de Lugo (Samos y Sarria)». Espacio, Tiempo y Forma. Serie I. Prehistoria y Arqueología 7: 153-189.

Rodriguez Resino, Á. (2006): Del Imperio Romano a la Alta Edad Media. Arqueología de la Tardoantigüedad en Galicia (siglos V-VIII). Noia, Toxosoutos.
Saguì, L. y Rovelli, A. (1998): «Residualità, non residualità, continuità di circolazione. Alcuni esempi dalla Crypta Balbi», en F. Guidobaldi, C. Pavolini y P. Pergola (eds.), I materiali residui nello scavo archeologico: 173-195. Roma, École Française de Rome.

Sánchez Pardo, J. C. (2010a): «Castros y aldeas galaicorromanas: sobre la evolución y transformación del poblamiento indígena en la Galicia romana». Zephyrus LXV: 129-148.

Sánchez Pardo, J. C. (2010b): «Poblamiento rural tardorromano y altomedieval en Galicia (ss.V-X). Una revisión arqueológica». Archeologia Medievale XXXVII: 285-306.

Sánchez Pardo, J. C. (2012): «Castros, castillos y otras fortificaciones en el paisaje sociopolítico de Galicia (siglos IV-XI)», en J. Quirós Castillo y J. M. Tejado Sebastián (eds.), Los castillos altomedievales en el noroeste de la Península Ibérica: 29-56. Bilbao, Universidad del País Vasco.

Sánchez Pardo, J. C. (2013): "Power and rural landscapes in early medieval Galicia (400-900 AD): towards a re-incorporation of the archaeology into the historical narrative". Early Medieval Europe 21, 2: $140-168$.

Sastre Blanco, J. C.; Catalán Ramos, R. y Fuentes Melgar, P. (2014): "El conjunto cerámico de El Castillón (Zamora) y las cerámicas de imitación de Sigillata en el contexto del siglo V", en R. Morais, A. Fernández y M. J. Sousa (eds.), As produçoes cerâmicas de imitaçao na Hispania: $537-$ 547. Porto, Faculdade de Letras da Universidade de Porto.

Schiffer, M. B. (1990): “Contexto arqueológico y contexto sistémico". Boletín de Antropología Americana 22: 81-93.

Tejerizo García, C. (2013): "La arquitectura doméstica en las aldeas meseteñas altomedievales", en J. A. Quirós Castillo (ed.), El poblamiento rural de época visigoda en Hispania. Arqueología del campesinado en el interior peninsular: 289-328. Bilbao, Universidad del País Vasco.

Tejerizo García, C. (2016): “Construyendo la casa por los cimientos: consideraciones acerca de la cerámica de la primera Alta Edad Media en la parte central de la cuenca del Duero", en J. A. Quirós Castillo y A. Vigil-Escalera (eds.), La cerámica de la Alta Edad Media en el cuadrante noroeste de la Península Ibérica (siglos $\mathrm{V}-\mathrm{X}$ ): sistemas de producción, mecanismos de distribución y patrones de consumo: 229254. Bilbao, Universidad del País Vasco. 
Tejerizo García, C. y Canosa Betés, J. (2018): “Power, control and social agency in post-roman northern Iberia: an archaeological analysis of hillfort occupations". Journal of Medieval Iberian Studies 10 (15): 1-29.

Tejerizo García, C.; Rodríguez González, C. y Fernández Pereiro, M. (2018): "Materiais cerámicos tardíos (ss. IV-VI d.C.) no castro de Viladonga". CROA. Boletín da Asociación de Amigos do Museo do Castro de Viladonga 28: 36-52.

Tejerizo García, C. y Vigil-Escalera Guirado, A. (2017): "Castro Ventosa y La Cabeza de Navasangil: una revisión de sus secuencias de ocupación y del fenómeno de los asentamientos fortificados altomedievales". Nailos 4: 129-161.

Tranoy, A. (1981): La Galice Romaine. Recherches sur le nord-ouest de la péninsule ibérique dans l'Antiquité. Paris, Publications du Centre Pierre Paris.

Vigil-Escalera, A. (2003): «Cerámicas tardorromanas y altomedievales de Madrid», en L. Caballero Zoreda, P. Mateos y M. Retuerce (eds.), Cerámicas tardorromanas y altomedievales en la Península Ibérica. Anejos de Archivo Español de Arqueología XXVIII: 371-387. Madrid, CSIC.

Vigil-Escalera, A. (2013): «Las últimas producciones de TSHT en el interior peninsular». Ex officina hispania. Cuadernos de la SECAH 1: 11-24.

Vigil-Escalera, A. (2015): Los primeros paisajes altomedievales en el interior de Hispania. Registros campesinos del siglo quinto d.C. Bilbao, Universidad del País Vasco.

Vigil-Escalera, A. y Quirós Castillo, J. A. (2016): La cerámica de la Alta Edad Media en el cuadrante noroeste de la Península Ibérica (siglos V-X). Bilbao, Universidad del País Vasco.

Vigil-Escalera, A. y Tejerizo García, C. (2014): «Asentamientos fortificados altomedievales en la Meseta: algunas distorsiones historiográficas», en R. Catalán Ramos, P. Fuentes Melgar y J. C. Sastre Blanco (eds.), Las fortificaciones en la tardoantigüedad. Élites y articulación del territorio (siglos V-VIII d.C.): 229-245. Madrid, La Ergástula. 